\title{
Introduction to Climate Change Over the Indian Region
}

\section{Coordinating Lead Authors}

R. Krishnan, Indian Institute of Tropical Meteorology (IITM-MoES), Pune, India C. Gnanaseelan, Indian Institute of Tropical Meteorology (IITM-MoES), Pune, India J. Sanjay, Indian Institute of Tropical Meteorology (IITM-MoES), Pune, India P. Swapna, Indian Institute of Tropical Meteorology (IITM-MoES), Pune, India Chirag Dhara, Indian Institute of Tropical Meteorology (IITM-MoES), Pune, India, e-mail: chirag.dhara@tropmet.res.in (corresponding author)

\section{Lead Authors}

T. P. Sabin, Indian Institute of Tropical Meteorology (IITM-MoES), Pune, India Jyoti Jadhav, Indian Institute of Tropical Meteorology (IITM-MoES), Pune, India N. Sandeep, Indian Institute of Tropical Meteorology (IITM-MoES), Pune, India Ayantika Dey Choudhury, Indian Institute of Tropical Meteorology (IITM-MoES), Pune, India Manmeet Singh, Indian Institute of Tropical Meteorology (IITM-MoES), Pune, India M. Mujumdar, Indian Institute of Tropical Meteorology (IITM-MoES), Pune, India Anant Parekh, Indian Institute of Tropical Meteorology (IITM-MoES), Pune, India Abha Tewari, (Formerly with Indian Air Force, National Health Systems Resource Center and Ministry of Environment Forest and Climate Change)

Rajeev Mehajan, Science and Engineering Research Board, Department of Science and Technology, Government of India, New Delhi, India

\section{Contributing Authors}

Rahul Chopra, TROP ICSU-Climate Education Project of the International Science Council at the Indian Institute of Science Education and Research (IISER), Pune, India Aparna Joshi, TROP ICSU-Climate Education Project of the International Science Council at the Indian Institute of Science Education and Research (IISER), Pune, India Anita Nagarajan, TROP ICSU - Climate Education Project of the International Science Council at the Indian Institute of Science Education and Research (IISER), Pune, India

Megha Nivsarkar, TROP ICSU—Climate Education Project of the International Science Council at the Indian Institute of Science Education and Research (IISER), Pune, India

\section{Review Editors}

M. Rajeevan, Ministry of Earth Sciences, Government of India, New Delhi, India M. Collins, Centre for Engineering, Mathematics and Physical Sciences, University of Exeter, Exeter, UK Dev Niyogi, Purdue University, West Lafayette, IN and University of Texas at Austin, Austin, TX, USA

\section{Corresponding Author}

Chirag Dhara, Indian Institute of Tropical Meteorology (IITM-MoES), Pune, India, e-mail: chirag.dhara@ tropmet.res.in

The original version of this chapter was revised. The caption of figure 1.5 has been changed. The correction to this chapter is available at https://doi.org/10.1007/978-981-15-4327-2_13 


\subsection{General Introduction}

The Earth's climate has varied considerably throughout its history. Periodic and episodic natural changes caused by natural climate forcings such as orbital variations and volcanic eruptions, and amplified by feedback processes intrinsic to the climate system, have induced substantial changes in planetary climate on a range of timescales.

Multiple independent lines of investigation have provided increasingly compelling evidence that human activities have significantly altered the Earth's climate since the industrial revolution (Stocker et al. 2013). A distinctive aspect of the present-day climate change is the rapid pace at which it is proceeding relative to that of natural variations alone; a pace that is unprecedented in the history of modern civilization.

The Earth's energy budget, which is the balance between the energy that the Earth receives from the Sun and the energy that it radiates back into space, is a key factor that determines the Earth's global mean climate. The composition of the atmosphere alters climate by modulating the incoming and outgoing radiative fluxes at the surface. The key drivers of present-day climate change are anthropogenic (human-caused) emissions of greenhouse gases (GHGs), aerosols and changes in land use and land cover (LULC).

GHGs warm the surface by reducing the amount of Earth's terrestrial radiation escaping directly to space. Atmospheric concentrations of the key GHGs - carbon dioxide, methane, and nitrous oxide - are now at higher levels than they have been at any time over the last 800,000 years, according to ice core records. In addition, their mean rates of increase over the past century are, with high confidence, unprecedented in the last 22,000 years (Stocker et al. 2013).

Aerosols are small particles or droplets suspended in the atmosphere produced from both natural and anthropogenic sources. Natural sources include mineral dust from soil erosion, sea salt and volcanic eruptions. Key anthropogenic sources are industrial air pollution, transport, and biomass burning, which produce airborne sulfates, nitrates, ammonium and black carbon, and dust produced by land degradation processes such as desertification. Aerosols tend to cool the surface by scattering or absorption of solar radiation (direct effect), or by enhancing cloud formation (indirect effect). Aerosol pollution, due to human activities, has thus offset a part of the warming caused by anthropogenic GHG emissions (Myhre et al. 2013).

Much of the Earth's land surface has been affected by considerable changes in land use and land cover (LULC) over the past few centuries (and even earlier), mainly because of deforestation and the expansion of agriculture. Deforested areas have a diminished capacity to act as a carbon dioxide sink and, if accompanied by biomass burning, are a direct source of GHGs. Conversion of land from natural vegetation to agriculture or pasturage also alters the terrestrial albedo, contributing to changes in the surface radiative balance.

The net effect of human-induced climate forcing has been an increase in the global average near-surface air temperature ${ }^{1}$ by approximately $1{ }^{\circ} \mathrm{C}$ since pre-industrial times (Allen et al. 2018). Each of the last three decades has been successively warmer at the Earth's surface than any preceding decade since 1850 (Stocker et al. 2013) and 2001-2018 have been 18 of the 19 warmest years in the observational record. Trends in other important global climate indicators such as rate and patterns of precipitation, temperature and precipitation extremes, atmospheric water vapour concentration, continental ice melt, sea-level rise, ocean heat content, ocean acidification and the frequency of powerful cyclones are consistent with the response expected from a warming planet (Stocker et al. 2013). At the current rate of temperature rise, it is likely ${ }^{2}$ that global warming will reach $1.5{ }^{\circ} \mathrm{C}$ between 2030 and 2052 (high confidence) (Allen et al. 2018) and $3-5{ }^{\circ} \mathrm{C}$ by the end of the century relative to pre-industrial times. Even if warming is limited to $1.5^{\circ} \mathrm{C}$ in the twenty-first century, certain slowly evolving changes such as ocean thermal expansion would persist well beyond 2100 causing sea levels to continue rising (high confidence).

While climate change is global, changes in climate are not expected to be uniform across the planet. For instance, Arctic temperatures are rising much faster than the global average (Stocker et al. 2013), and rates of sea-level rise vary significantly across the world (Church et al. 2013). Changes in climate at regional scales are not understood as robustly as at the global scale due to insufficient local observational data or understanding of physical phenomena specific to given regions (Flato et al. 2013). Yet, knowledge of present and expected changes in regional climate is critical to people and policymakers to plan for disaster management, risk mitigation and for formulating locally relevant adaptation strategies (Burkett et al. 2014).

The regional climate over the Indian subcontinent involves complex interactions of the atmosphere-oceanland-cryosphere system on different space and time scales. In addition, there is evidence that anthropogenic activities have influenced the regional climate in recent decades. Impacts associated with human-induced climate change such as increasing heat extremes, changing monsoon patterns and sea-level rise pose serious threats to lives and livelihoods on the subcontinent. This makes it necessary to understand how and why the climate is changing across India and how these changes are expected to evolve in the future. The following

\footnotetext{
${ }^{1}$ The 'near surface air temperature' is defined as the temperature $2 \mathrm{~m}$ above the surface over land areas, and as the sea surface temperature (SST) for oceanic areas.

${ }^{2}$ Defined in Box 1.4.
} 
section provides a brief overview of the mean climate of the Indian subcontinent and sets the context for understanding the key aspects of climate change in the region.

\subsubsection{Setting the Regional Context}

The distinct topographical and geographical features of the Indian subcontinent endow the region with widely varying climatic zones ranging from the arid Thar desert in the north-west, Himalayan tundra in the north, humid areas in the southwest, central and northeastern parts, together with diverse microclimatic areas that spread across the vast subcontinent. A dominant feature of the regional climate is the Indian Summer Monsoon (ISM), which is characterized by pronounced seasonal migrations of the tropical rain belts associated with the Inter-tropical Convergence Zone (ITCZ), along with large-scale seasonal wind reversals (Gadgil 2003; Schneider et al. 2014).

The Himalayas and the Hindu Kush mountains protect the Indian subcontinent from large-scale incursions of cold extra-tropical winds during the winter season. Additionally, the seasonal warming of the Himalayas and the Tibetan Plateau during the boreal summer sets up a north-south thermal contrast relative to the tropical Indian Ocean, which is important for initiating the large-scale summer monsoon circulation. The climatological seasons in India are broadly classified as the winter (December-January-February), pre-monsoon (MarchApril-May), summer monsoon (June-July-August-September) and the post-monsoon (October-November) seasons. A distinction of India's climate is the exceptionally strong seasonal cycle of winds and precipitation (Turner and Annamalai 2012). The Indian summer monsoon, also known as the South Asian monsoon, is a major component of the global climate (see Box 1.1 for a summary of monsoon processes over the Indian subcontinent). In addition to monsoonal rains, areas in the western Himalayas (WH) also receive substantial precipitation during the winter and early spring months from eastward propagating synoptic-scale weather systems known as the Western Disturbances that originate from the Mediterranean region (e.g. Dimri et al. 2015; Hunt et al. 2018; Krishnan et al. 2019a, b) (Chap. 11). The Indian region is also prone to a wide range of severe weather events and climate extremes, including tropical cyclones, thunderstorms, heat waves, floods, droughts, among others.

\section{Box 1.1: Monsoon Processes over the Indian subcontinent}

Large-scale orographic features such as the Himalayas and the Tibetan Plateau (e.g. Boos and Kuang 2010; Turner and Annamalai 2012 and references therein); as well as narrow mountains such as the Western Ghats along the Indian west coast and the Arakan Yoma mountains along the Myanmar coast (e.g. Xie et al. 2006; Rajendran and Kitoh 2008; Krishnan et al. 2013; Sabin et al. 2013) exert control on the distribution of monsoon precipitation over the Indian subcontinent. With moisture-laden winds from the Arabian Sea, the Bay of Bengal and the Indian Ocean feeding bountiful rains over vast areas in central-north and northeast India, Western Ghats and peninsular India, central-eastern Himalayas; the summer monsoon activity is sustained through feedbacks between the monsoon circulation and the release of latent heat of condensation by moist convective processes (Rao 1976; Krishnamurti and Surgi 1987).

The ISM is home to a variety of precipitation producing systems, which include-monsoon onset vortices, meso-scale systems and orographic precipitation, westnorth-west moving synoptic systems (lows and depressions) from the Bay of Bengal and Southeast Asia, slow northward and westward propagating large-scale organized rainbands and mid-tropospheric cyclones, to name a few (Rao 1976). Interactions among multiple scales of motion (i.e. planetary, regional, synoptic, meso and cumulus scales) render significant spatio-temporal heterogeneity in the monsoon rainfall distribution over the region. Warm rain processes during the summer monsoon region are recognized to be dominant over the Western Ghats and other areas in India, as evidenced from the Tropical Rainfall Measurement Mission (TRMM) Precipitation Radar (PR) satellite (e.g. Shige et al. 2017) and aircraft measurements (e.g. Konwar et al. 2014). There has been improved understanding of the three-dimensional structure of latent heating associated with convective and stratiform clouds during the summer monsoon season based on the TRMM satellite observations (e.g. Houze 1997; Houze et al. 2007; Stano et al. 2002; Romatschke and Houze 2011); as well as the monsoonal circulation response to latent heating based on numerical simulation experiments (e.g. Choudhury and Krishnan 2011; Choudhury et al. 2018) in the recent decades.

Several areas in south-eastern peninsular India, including areas covering the states of Tamil Nadu and Andhra Pradesh, receive considerable rainfall during the northeast monsoon (October-December) (Rajeevan et al. 2012). The northeast monsoon develops following the withdrawal of the summer monsoon rainy season when the northern landmass of India and the Asian continent begins to cool off rapidly so that high-pressure builds over northern India. The northeasterly monsoon winds from the northern areas gather moisture from the Bay of Bengal and contribute to precipitation over peninsular India and parts of Sri Lanka (Turner and Annamalai 2012). 


\subsubsection{Key Scientific Issues}

Climate over the Indian subcontinent has varied significantly in the past century in response to natural variations (e.g. Box 1.2 on the variability of the ISM) and anthropogenic forcing (see Box 1.3). In recent times, there has been considerable progress in understanding the influence of anthropogenic climate change over the Indian subcontinent, particularly the regional monsoon.

State-of-the-art climate models project a continuation of anthropogenic global warming and associated climate change during the twenty-first century, the impacts of which have profound implications for India. Yet, there remain substantial knowledge gaps with regard to climate projections, particularly at smaller spatial and temporal scales. For instance, CMIP5 simulations of historical and future changes in the monsoon rainfall exhibit wide variations across the Indian region (Sperber et al. 2013; Turner and Annamalai 2012), posing difficulties for policy making. Likewise, it is necessary to reduce the range among climate models projections of future changes in Indian Ocean warming, regional sea-level rise, tropical cyclone activity, weather and climate extremes, changes in the Himalayan snow cover, etc. It is essential to deepen our understanding of the science of climate change, improve the representation of key processes in climate models (e.g. clouds, aerosol-cloud interactions, vegetation-atmosphere feedbacks, etc.) and also build human capacity to address these challenges.

Efforts in these directions have already begun in India. One such initiative is the development of an Earth System Model (IITM-ESM) at the Centre for Climate Change Research (CCCR) in the Indian Institute of Tropical Meteorology (Swapna et al. 2018). A brief discussion of the IITM-ESM is provided in the following section.

\section{Box 1.2: Indian Summer Monsoon Variability}

The ISM also exhibits a rich variety of natural variations on different timescales ranging across subseasonal/ intra-seasonal, interannual (year-to-year), multi-decadal and centennial timescales, which are evident from instrumental records and paleoclimate reconstructions (e.g. Turner and Annamalai 2012; Sinha et al. 2015). The sub-seasonal/intra-seasonal variability of the ISM is dominated by active and break monsoon spells (e.g. Rajeevan et al. 2010) and the interannual variability is associated with excess or deficient seasonal monsoon rainfall over India (e.g. Pant and Parthasarathy 1981). The interannual and decadal timescale variations in the ISM rainfall are known to have links with the tropical Pacific, Indian and Atlantic oceans, particularly with climate drivers such as the El Nino/Southern Oscillation (ENSO), Indian Ocean Dipole (IOD), Equatorial Indian Ocean Oscillation (EQUINOO), Pacific Dedacal Oscillation
(PDO), etc. The reader is referred to Chap. 3 for more details on the ISM variability and associated teleconnections.

\section{Box 1.3 Anthropogenic Drivers of Climate Change}

Changes in the atmospheric concentration of GHGs, aerosols and LULC are the key anthropogenic drivers of global climate change.

The global atmospheric carbon dioxide concentration has increased from an average of $280 \mathrm{ppm}$ in the pre-industrial period to over 407 ppm in 2018 (https:// scripps.ucsd.edu/programs/keelingcurve/), contributing a radiative forcing (RF) of about $2.1 \mathrm{~W} / \mathrm{m}^{2}$ at the top of the atmosphere.

Unlike GHGs, which are well-mixed in the atmosphere, the concentration of anthropogenic aerosols in the atmosphere exhibits large spatio-temporal variability and complex interactions with clouds and snow, giving rise to uncertainties in the estimation of the aerosol RF. The IPCC AR5 estimated the globally averaged total aerosol effective radiative forcing (excluding black carbon on snow and ice) to be in the range -1.9 to $-0.1 \mathrm{~W} / \mathrm{m}^{2}$. Over India, the direct aerosol RF is estimated to range from -15 to $+8 \mathrm{~W} / \mathrm{m}^{2}$ at the top of the atmosphere and -49 to $-31 \mathrm{~W} / \mathrm{m}^{2}$ at the surface (Nair et al. 2016) (Chap. 5). The implications are that aerosol RF can be significantly larger than the GHG forcing at regional scales and large gradients in the aerosol RF can significantly perturb the regional climate system.

The IPCC AR5 reported a globally averaged RF due to anthropogenic changes in LULC to be about $-0.2 \mathrm{~W} / \mathrm{m}^{2}$ although it was anticipated that this estimate may be revised downwards with emerging research. As with aerosols, there are large spatiotemporal variations in RF due to LULC changes at regional scales.

Despite the uncertainties in the estimation of RF due to anthropogenic aerosol and LULC changes, there is high confidence that they have offset a substantial portion of the effect of GHGs on both temperature and precipitation (IPCC AR5).

\subsubsection{IITM-ESM: A Climate Modelling Initiative from India}

The Coupled Model Intercomparison Project (CMIP) organized under the auspices of the World Climate Research Programme (WCRP) forms the basis of the climate projections in the IPCC Assessment Reports. The CMIP experiments have evolved over six phases (Meehl et al. 2000; 
Fig. 1.1 Schematic of IITM Earth system model (IITM-ESM)

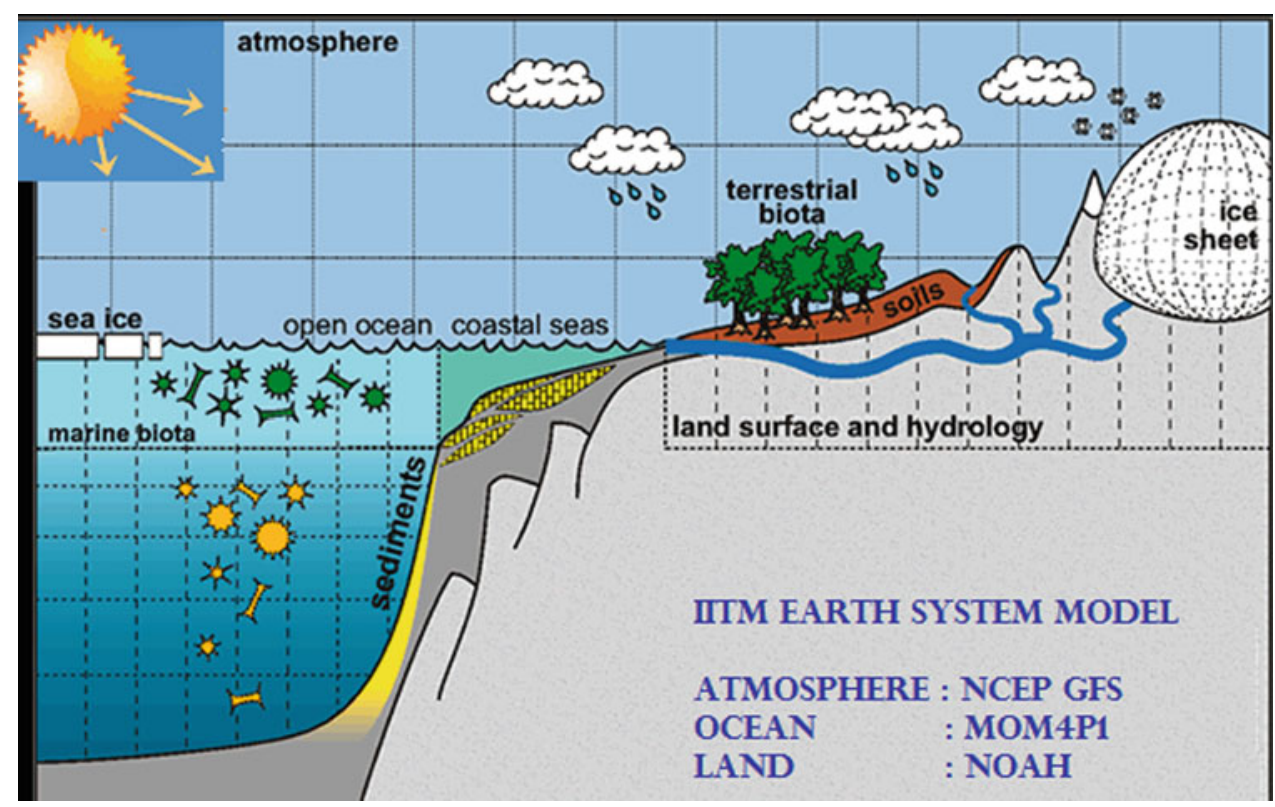

Meehl and Hibbard 2007; Taylor et al. 2012; Eyring et al. 2016) and become a central element of national and international assessments of climate change.

The IITM-Earth System Model (IITM-ESM) has contributed to the CMIP6 and IPCC AR6 assessments, the first time from India. The philosophy behind the development of the IITM-ESM is to create capabilities in global modelling, with special emphasis on the South Asian monsoon, to address the science of climate change, including detection, attribution and future projections of global and regional climate.

The IITM-ESM is configured using an atmospheric general circulation model based on the National Centers for Environmental Prediction (NCEP) Global Forecast System (GFS) with a global spectral triangular truncation of 62 waves (T62, grid size $\sim 200 \mathrm{~km}$ ) and 64 vertical levels with top model layer extending up to $0.2 \mathrm{hPa}$, a global ocean component based on the Modular Ocean Model Version 4p1 (MOM4p1) having a resolution of $\sim 100 \mathrm{~km}$ with finer resolution $(\sim 35 \mathrm{~km})$ near-equatorial regions with 50 levels in the vertical, a land surface model (Noah LSM) with four layers and a dynamical sea ice model known as the Sea Ice Simulator (SIS). The details about IITM-ESM are described in Swapna et al. (2015). A schematic of the IITM-ESM is shown in Fig. 1.1.

\subsection{Global and Regional Climate Change}

This section provides a summary of assessments of the observed and projected changes in the global climate and regional climate over India, based on published scientific literature, key findings from the individual chapters of this report, together with analyses of observed and reanalysis datasets, and diagnoses from the CMIP, CORDEX and IITM-ESM model simulations.

\subsubsection{Observed Changes in Global Climate}

The evidence for a warming world comes from multiple independent climate indicators in the atmosphere and oceans (Hartmann et al. 2013). They include changes in surface, atmospheric and oceanic temperatures, glaciers, snow cover, sea ice, sea-level rise, atmospheric water vapour, extreme events and ocean acidification.

Inferences of past climate from paleo-climate proxies suggest that recent changes in global surface temperature are unusual and natural processes alone cannot explain the rapid rate of warming in the industrial era. Computerbased climate models are unable to replicate the observed warming unless the effect of human-induced changes such as emissions of GHGs and aerosols, and changes in land use and land cover are included (Bindoff et al. 2013).

The Global Mean Surface Temperature (GMST) comprising the global land surface air temperature (LSAT) and sea surface temperature (SST) is a key metric in the climate change policy framework. Historical records of GMST extend back farther than any other global instrumental series making it the key to understanding the patterns and magnitude of natural climate variations and distinguishing them from anthropogenically forced climate change (Fig. 1.2).

The Fifth Assessment Report by the Intergovernmental Panel on Climate Change (IPCC AR5) concluded that it is 


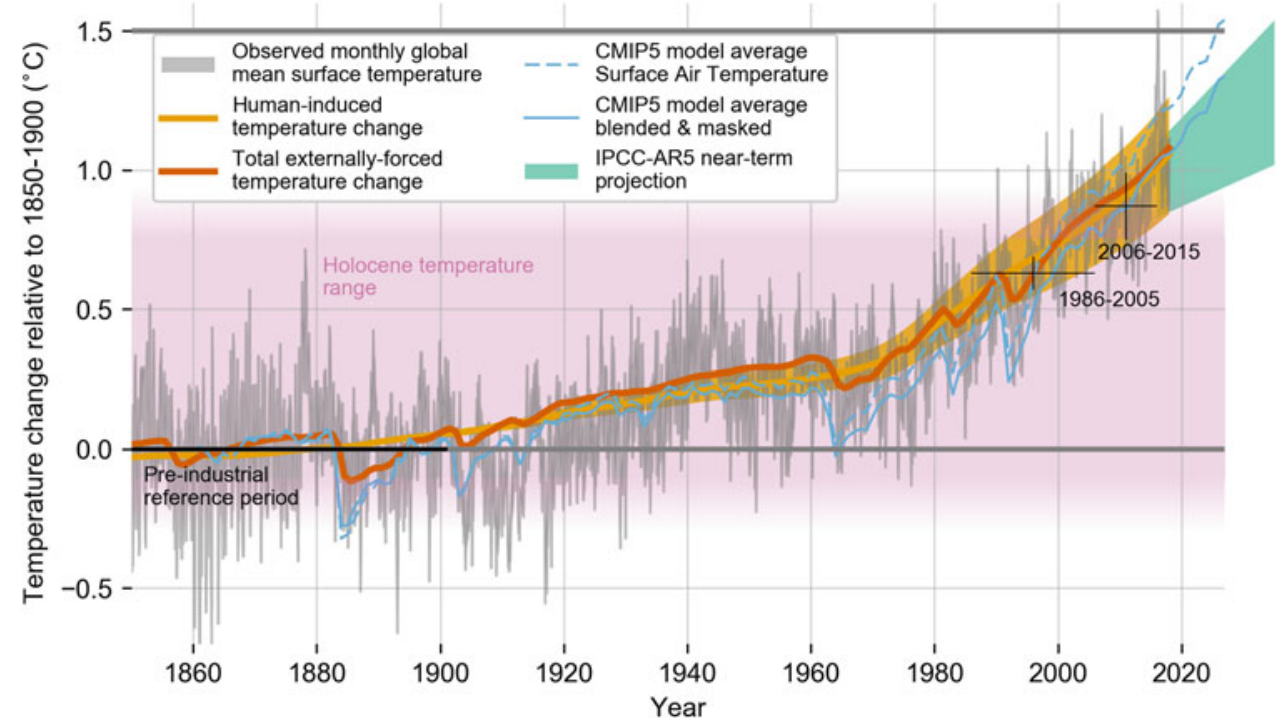

Fig. 1.2 Evolution of global mean surface temperature (GMST) over the period of instrumental observations. Grey-shaded line shows monthly mean GMST in the HadCRUT4, NOAAGlobalTemp, GISTEMP and Cowtan-Way datasets, expressed as departures from 1850 to 1900 , with varying grey line thickness indicating inter-dataset range. All observational datasets shown represent GMST as a weighted average of near-surface air temperature over land and sea surface temperature over oceans. Human-induced (yellow) and total (humanand naturally forced, orange) contributions to these GMST changes are shown calculated following Otto et al. (2015) and Haustein et al. (2017). Fractional uncertainty in the level of human-induced warming in 2017 is set equal to $\pm 20 \%$ based on multiple lines of evidence. Thin blue lines show the modelled global mean surface air temperature (dashed) and blended surface air and sea surface temperature accounting for observational coverage (solid) from the CMIP5 historical ensemble average extended with RCP8.5 (Defined in the following section) forcing (Cowtan et al. 2015; Richardson et al. 2018). The pink shading indicates a range for temperature fluctuations over the Holocene (Marcott et al. 2013). Light green plume shows the AR5 prediction for average GMST over 2016-2035 (Kirtman et al. 2013). Reproduced from Allen et al. 2018 (Fig. 1.2)

According to IPCC AR5, anthropogenic forcing has contributed substantially to upper-ocean warming (above $700 \mathrm{~m}$ ). On a global scale, ocean warming is largest near the surface, with the upper $75 \mathrm{~m}$ having warmed by 0.11 [0.09 to 0.13 ] ${ }^{\circ} \mathrm{C}$ per decade over the period 1971-2010 (Stocker et al. 2013).

Warming is expected to elevate the rate of evaporation and increase the moisture content of the atmospheric. Indeed, the amount of water vapour in the atmosphere, measured as specific humidity, has increased globally over both the land and ocean. IPCC AR5 summarized that it is very likely that global near-surface air specific humidity has increased since the 1970s (Hartmann et al. 2013). However, during recent years the near-surface moistening over land has abated (medium confidence). As a result, fairly widespread decreases in relative humidity near the surface are observed over land in recent years.

IPCC AR5 concluded that confidence in precipitation change averaged over global land areas since 1901 is low for years prior to 1951 and medium afterwards. Averaged over the mid-latitude land areas of the northern hemisphere, precipitation has likely increased since 1901 (medium confidence before and high confidence after 1951) (Hartmann et al. 2013). Precipitation in tropical land areas has increased areas of the planet. 
(medium confidence) over the decade ending in 2012, reversing the drying trend that occurred from the mid-1970s to mid-1990s. Human influence has also contributed to large-scale changes in precipitation patterns over land (medium confidence; Bindoff et al. 2013). It is likely that, since about 1950 , the number of heavy precipitation events over land has increased in more regions than it has decreased.

Local changes in temperature affect the cryosphere. The amount of ice contained in glaciers globally has been declining every year for over 20 years. Total ice loss from the Greenland and Antarctic ice sheets during 1992-2011 (inclusive) has been 4260 [3060-5460] Gt, equivalent to 11.7 [8.4-15.1] $\mathrm{mm}$ of sea level. However, the rate of change has increased with time and most of this ice has been lost in the second decade of the 20-year period (Vaughan et al. 2013).

The global average sea level rose by $19 \mathrm{~cm}$ from 1901 to 2010 (Stocker et al. 2013). The average rate of rise measured by satellites has been 3.2 [2.9-3.5] mm/year since the $1990 \mathrm{~s}$ up from 1.7 [1.5-1.9] mm/year during the twentieth century, obtained from historical tide gauge records (Hartmann et al. 2013). Thermal expansion and glacier melt because of anthropogenic global warming have been the major drivers of rise in global sea levels over the past century.

Substantial losses in Arctic sea ice have been observed since satellite records began, particularly at the time of the minimum extent, which occurs in September, at the end of the annual melt season. In contrast, there has been an increase in Antarctic sea ice, but with a smaller rate of change than in the Arctic.

Snow cover is sensitive to changes in temperature, particularly during the spring, when the snow starts to melt. Spring snow cover has shrunk across the northern hemisphere since the 1950s. IPCC AR5 concluded that it is likely that snowfall events are decreasing in most regions (North America, Europe, Southern and East Asia) where increased winter temperatures have been observed (Hartmann et al. 2013). The total seasonal snowfall is reported to be declining along with increase in maximum and minimum temperatures in the western Himalaya. Confidence is low for changes in snowfall over Antarctica.

Uptake of anthropogenic $\mathrm{CO}_{2}$ by the ocean increases the hydrogen ion concentration in the ocean water, causing acidification. There is high confidence that the global average $\mathrm{pH}$ of the surface ocean has decreased by $0.1 \mathrm{pH}$ units since the beginning of the industrial era, corresponding to an approximately 30\% increase in acidity (Stocker et al. 2013).

\subsubsection{Projected Changes in Global Climate}

This section assesses projected long-term changes in the global climate system during the twenty-first century. These changes are expected to be larger than the internal variability of the climate system and to depend primarily on how anthropogenic emissions change the atmospheric composition in the future. Aerosol emissions are projected to decline in the coming decades, and it is expected that future changes will be dominated by the increasing concentrations of GHGs.

Climate models are used to study the response of the climate system to anthropogenic activity (also referred to as 'external forcing'). Towards studying how the climate will change in the twenty-first century, several standardized scenarios have been developed, each with a specific description of how human-induced changes would affect the planet's energy budget. Differences between scenarios are based on underpinning assumptions about future changes in fossil fuel consumption, land use change, etc., and were developed using integrated assessment models that combined economic, demographic and policy modelling, with simplified physical climate models in order to simulate the global economic impacts of climate change under different mitigation scenarios (Calel and Stainforth 2017).

Earth system models, developed by climate modelling groups worldwide, perform climate change simulations for these forcing scenarios, whose standardization facilitates easy intercomparison between the results of these studies.

The scenarios used by models participating in the Coupled Model Intercomparison Project Phase 5 (CMIP5) that contributed to the IPCC AR5 were termed the Representative Concentration Pathways (RCPs) and covered the period from 2006 to 2100 (van Vuuren et al. 2011). The four RCPs that were defined were the RCP2.6, representing a low emissions pathway resulting in radiative forcing (RF) of roughly $2.6 \mathrm{~W} / \mathrm{m}^{2}$ at the end of the twenty-first century, RCP4.5 and RCP6 representing intermediate emission pathways resulting in an RF of $4.5 \mathrm{~W} / \mathrm{m}^{2}$ and $6 \mathrm{~W} / \mathrm{m}^{2}$, respectively and the high emissions scenario RCP8.5 representing a pathway with continued growth in GHG emissions leading to an RF of roughly $8.5 \mathrm{Wm}^{-2}$ at the end of the twenty-first century. Various chapters of this report mainly use the RCP pathways to study future changes in the climate system.

The AR5 assessment concluded that GMST will continue to rise over the twenty-first century with increasing GHGs. The increase in GMST for 2081-2100, relative to 19862005 will likely be in the 5-95\% range of $0.3-1.7^{\circ} \mathrm{C}$ under RCP2.6 and 2.6-4.8 ${ }^{\circ} \mathrm{C}$ under RCP8.5 (Collins et al. 2013). Assessment of precipitation based on CMIP5 models indicates that it is virtually certain that global mean precipitation will increase by more than $0.05 \mathrm{~mm} \mathrm{day}^{-1}$ and $0.15 \mathrm{~mm}$ day $^{-1}$ by the end of the twenty-first century under the RCP2.6 and RCP8.5 scenarios, respectively (Collins et al. 2013). The median of the global mean sea-level rise for the period $2081-2100$ is $0.47 \mathrm{~m}$ in RCP4.5 and $0.63 \mathrm{~m}$ in the 
Table 1.1 Change in surface air temperature (TAS, ${ }^{\circ} \mathrm{C}$ ) and precipitation (PR, mm day ${ }^{-1}$ ) relative to $1850-1900$ for the RCP4.5 and $\mathrm{RCP} 8.5$ scenarios from CMIP5 models for the Global and the Indian region during the historical (1951-2014), near future (2040-2069) and far future (2070-2099) periods

\begin{tabular}{|c|c|c|c|c|c|c|c|c|c|c|}
\hline \multirow[t]{4}{*}{ Variables } & \multicolumn{10}{|c|}{ Estimates from CMIP5; (base period 1850-1900) } \\
\hline & \multicolumn{5}{|c|}{ Global mean estimates } & \multicolumn{5}{|c|}{ Indian region estimates } \\
\hline & \multirow{2}{*}{$\begin{array}{l}\text { Historical } \\
1951- \\
2014\end{array}$} & \multicolumn{2}{|l|}{$\mathrm{RCP} 4.5$} & \multicolumn{2}{|l|}{ RCP8.5 } & \multirow{2}{*}{$\begin{array}{l}\text { Historical } \\
1951- \\
2014\end{array}$} & \multicolumn{2}{|c|}{$\mathrm{RCP} 4.5$} & \multicolumn{2}{|l|}{ RCP8.5 } \\
\hline & & $\begin{array}{l}2040- \\
2069\end{array}$ & $\begin{array}{l}2070- \\
2099\end{array}$ & $\begin{array}{l}2040- \\
2069\end{array}$ & $\begin{array}{l}2070- \\
2099\end{array}$ & & $\begin{array}{l}2040- \\
2069\end{array}$ & $\begin{array}{l}2070- \\
2099\end{array}$ & $\begin{array}{l}2040- \\
2069\end{array}$ & $\begin{array}{l}2070- \\
2099\end{array}$ \\
\hline TAS $\left({ }^{\circ} \mathrm{C}\right)$ & $\begin{array}{l}0.54 \\
(0.28 \text { to } \\
0.68)\end{array}$ & $\begin{array}{l}2.16 \\
(1.43 \text { to } \\
2.75)\end{array}$ & $\begin{array}{l}2.62 \\
(1.80 \text { to } \\
3.16)\end{array}$ & $\begin{array}{l}2.75 \\
(1.94 \text { to } \\
3.48)\end{array}$ & $\begin{array}{l}4.31 \\
(3.08 \text { to } \\
5.25)\end{array}$ & $\begin{array}{l}0.72 \\
(0.47 \text { to } \\
1.28)\end{array}$ & $\begin{array}{l}2.67 \\
(1.72 \text { to } \\
3.70)\end{array}$ & $\begin{array}{l}3.27 \\
(2.25 \text { to } \\
4.27)\end{array}$ & $\begin{array}{l}3.37 \\
(2.32 \text { to } \\
4.68)\end{array}$ & $\begin{array}{l}5.33 \\
(3.70 \text { to } \\
6.11)\end{array}$ \\
\hline $\begin{array}{l}\text { Precip. (mm } \\
\text { day }^{-1} \text { ) }\end{array}$ & $\begin{array}{l}0.01 \\
(-0.02 \text { to } \\
0.40)\end{array}$ & $\begin{array}{l}0.09 \\
(0.05 \text { to } \\
0.16)\end{array}$ & $\begin{array}{l}0.13 \\
(0.09 \text { to } \\
0.18)\end{array}$ & $\begin{array}{l}0.12 \\
(0.07 \text { to } \\
0.20)\end{array}$ & $\begin{array}{l}0.20 \\
(0.11 \text { to } \\
0.30)\end{array}$ & $\begin{array}{l}-0.06 \\
(-0.36 \text { to } \\
0.28)\end{array}$ & $\begin{array}{l}0.10 \\
(-0.32 \\
\text { to } 0.33)\end{array}$ & $\begin{array}{l}0.23(- \\
0.13 \text { to } \\
0.49)\end{array}$ & $\begin{array}{l}0.22 \\
(-0.09 \\
\text { to } 0.43)\end{array}$ & $\begin{array}{l}0.28 \\
(-0.31 \\
\text { to } 0.68)\end{array}$ \\
\hline
\end{tabular}

Included are CMIP5 multi-model means and range (in parenthesis) among models. Models used for this analysis are listed in Table 1.3

RCP8.5 scenario (Church et al. 2013). The corresponding increase in the thermosteric sea level is $0.2 \mathrm{~m}$ for RCP4.5 and $0.27 \mathrm{~m}$ for the RCP8.5 scenario. A summary of projections for temperature and precipitation from CMIP5 models, averaged globally and over India, are provided in Table 1.1.

In the upcoming IPCC Sixth Assessment Report (IPCC AR6), projections are utilizing the a new range of scenarios known as Shared Socio-economic Pathways (SSPs) (O'Neill et al. 2017) introduced in the Coupled Model Intercomparison Project Phase 6 (CMIP6). The SSPs define five different ways in which the world might evolve in the absence of climate policy and how different levels of climate change mitigation could be achieved when the mitigation targets of RCPs are combined with the SSPs. These include SSP1: a world of sustainability-focused growth and equality; SSP2: a 'middle of the road' world where trends broadly follow their historical patterns; SSP3: a fragmented world of 'resurgent nationalism'; SSP4: a world of ever-increasing inequality and SSP5: a world of rapid and unconstrained growth in economic output and energy use.

Projections by the IITM-ESM of changes in key climate variables based on different SSP scenarios are discussed in detail in Sect. 1.2.3. A summary of these projections for temperature and precipitation, including those from other CMIP6 models, can be found in Table 1.2.

\footnotetext{
${ }^{3}$ Throughout this report, climate change projections refer to changes in the 'near future' and 'far future' relative to a specified historical baseline period. 'Near future' refers to the climatological average over the period 2040-2069 and is used interchangeably with 'middle of the century'. Likewise 'far future' refers to the climatological average over the period 2070-2099 and is used interchangeably with 'end of the century'.
}

\subsubsection{Contribution from IITM-ESM}

In this section, we assess changes in the major global indicators of climate change using the IITM-ESM CMIP6 simulations. Change is assessed relative to the pre-industrial period (1850-1900). Simulations spanning over the historical period (1950-2014), near future (2040-2069) ${ }^{3}$ and far future (2070-2099) are presented along with simulations from other available CMIP6 models. The projections are based on the Shared Socio-economic Pathways. Two of the priority SSPs, the SSP2-4.5 considered as middle-of-the-road and SSP5-8.5 as fossil-fuel-rich development, are presented in this section.

Changes in selected global climate indices including Global Mean Surface Temperature (GMST), global mean precipitation and Global Mean thermosteric Sea Level (GMSL) for the period 1900-2099 are shown in Fig. 1.3. These include historical simulations for the period 19002014 and projections from 2015 onwards. The historical simulations enable evaluation of model performance w.r.t observations and show whether the models are able to reproduce the observed aspects of climate change and variability. The time-series of GMST show an increase of more than $0.6{ }^{\circ} \mathrm{C}$ during 1951-2014 (with reference to a base period of 1900-1930). However, the increase is not steady; warming is more pronounced since 1970 and a slowing down of warming occurred during the recent period with a slow down in global warming (2000-2010). These fluctuations arise from natural variations within the climate system or internal climate variability, and are also driven by external forcings. The CMIP6 models simulate the observed warming trend but exhibit a wide range of warming levels especially in the far future (Fig. 1.3a). The higher warming level in the CMIP6 models may be associated with higher Equilibrium Climate Sensitivity (ECS). The GMST from the IITM-ESM for the historical period closely follows the observed warming (figure not shown), and the global mean temperature rise 
Table 1.2 Change in near-surface air temperature (TAS, ${ }^{\circ} \mathrm{C}$ ) and precipitation (Precip, $\mathrm{mm} \mathrm{day}^{-1}$ ) relative to $1850-1900$ for the SSP2-4.5 and SSP5-8.5 scenarios from IITM-ESM and CMIP6 models for the Global and the Indian region during the historical (1951-2014), near future (20402069) and far future (2070-2099) periods

\begin{tabular}{|c|c|c|c|c|c|c|c|c|c|c|c|}
\hline \multirow[t]{4}{*}{ Variables } & & \multicolumn{10}{|c|}{ Estimates from CMIP6 \& IITM-ESM (base period 1850-1900) } \\
\hline & & \multicolumn{5}{|c|}{ Global mean estimates } & \multicolumn{5}{|c|}{ Indian region estimates } \\
\hline & & \multirow{2}{*}{\begin{tabular}{|l} 
Historical \\
1951 \\
2014
\end{tabular}} & \multicolumn{2}{|c|}{ SSP2-45 } & \multicolumn{2}{|l|}{ SSP5-85 } & \multirow{2}{*}{$\begin{array}{l}\text { Historical } \\
1951- \\
2014\end{array}$} & \multicolumn{2}{|c|}{ SSP2-45 } & \multicolumn{2}{|l|}{ SSP5-85 } \\
\hline & & & $\begin{array}{l}2040- \\
2069\end{array}$ & $\begin{array}{l}2070- \\
2099\end{array}$ & $\begin{array}{l}2040- \\
2069\end{array}$ & $\begin{array}{l}2070- \\
2099\end{array}$ & & $\begin{array}{l}2040- \\
2069\end{array}$ & $\begin{array}{l}2070- \\
2099\end{array}$ & $\begin{array}{l}2040- \\
2069\end{array}$ & $\begin{array}{l}2070- \\
2099\end{array}$ \\
\hline \multirow[t]{2}{*}{$\begin{array}{l}\text { TAS } \\
\left({ }^{\circ} \mathrm{C}\right)\end{array}$} & CMIP6 & $\begin{array}{l}0.59 \\
(0.32 \text { to } \\
1.07)\end{array}$ & $\begin{array}{l}2.5 \\
(1.60 \text { to } \\
3.28)\end{array}$ & $\begin{array}{l}3.16 \\
(1.96 \text { to } \\
4.05)\end{array}$ & $\begin{array}{l}3.13 \\
(1.87 \text { to } \\
4.11)\end{array}$ & $\begin{array}{l}5.0 \\
(2.93 \text { to } \\
6.55)\end{array}$ & $\begin{array}{l}0.50 \\
(0.29 \text { to } \\
0.87)\end{array}$ & $\begin{array}{l}2.37 \\
(1.67 \text { to } \\
3.16)\end{array}$ & $\begin{array}{l}3.14 \\
(2.11 \text { to } \\
4.48)\end{array}$ & $\begin{array}{l}3.04 \\
(1.92 \text { to } \\
4.53)\end{array}$ & $\begin{array}{l}5.35 \\
(3.26 \text { to } \\
7.30)\end{array}$ \\
\hline & $\begin{array}{l}\text { IITM- } \\
\text { ESM }\end{array}$ & 0.60 & 1.91 & 2.22 & 2.28 & 3.36 & 0.54 & 1.67 & 2.11 & 2.08 & 3.26 \\
\hline \multirow[t]{2}{*}{ Precip. $\left(\mathrm{mm} \mathrm{day}^{-1}\right)$} & CMIP6 & $\begin{array}{l}0.01 \\
(0.00 \text { to } \\
0.05)\end{array}$ & $\begin{array}{l}0.11 \\
(0.04 \text { to } \\
0.19)\end{array}$ & $\begin{array}{l}0.15 \\
(0.06 \text { to } \\
0.24)\end{array}$ & $\begin{array}{l}0.13 \\
(0.04 \text { to } \\
0.21)\end{array}$ & $\begin{array}{l}0.21 \\
(0.09 \text { to } \\
0.32)\end{array}$ & $\begin{array}{l}0.01 \\
(-0.30 \text { to } \\
0.31)\end{array}$ & $\begin{array}{l}0.33 \\
(-0.36 \\
\text { to } 1.38)\end{array}$ & $\begin{array}{l}0.45 \\
(-0.60 \\
\text { to } 1.60)\end{array}$ & $\begin{array}{l}0.49 \\
(-0.20 \\
\text { to } 0.96)\end{array}$ & $\begin{array}{l}0.84 \\
(-0.25 \\
\text { to } 1.89)\end{array}$ \\
\hline & $\begin{array}{l}\text { IITM- } \\
\text { E5M }\end{array}$ & 0.02 & 0.09 & 0.11 & 0.09 & 0.15 & -0.02 & 0.25 & 0.03 & 0.16 & 0.5 \\
\hline
\end{tabular}

The estimates for CMIP6 constitute the multi-model mean and range (in parenthesis) across the considered models. The CMIP6 models used for this analysis are listed in Table 1.4

is within the range of warming shown by other CMIP6 models during the historical period (Fig. 1.3a).

A consistent feature across climate projections is a continuous rise in global mean temperature (Fig. 1.3a). The evolution of GMST for the future scenarios from the AR5 assessment concluded that GMST will continue to rise over the twenty-first century with the increase in GHGs. The GMST change at the end of the twenty-first century w.r. t. the pre-industrial period (1850-1900) from IITM-ESM under the highest emissions scenario (SSP5-8.5), is $3.4{ }^{\circ} \mathrm{C}$ and under the intermediate emissions scenarios (SSP2-4.5), is about $2.2{ }^{\circ} \mathrm{C}$, respectively. The corresponding increase in
GMST in CMIP6 models show a range of about $2.9{ }^{\circ} \mathrm{C}-$ $6.5{ }^{\circ} \mathrm{C}$ and $2{ }^{\circ} \mathrm{C}-4.1{ }^{\circ} \mathrm{C}$ under SSP5-8.5 and SSP2-4.5, respectively. The increase in the mean surface temperature over the Indian region projected by the IITM-ESM is $2.1^{\circ} \mathrm{C}$ and $3.3{ }^{\circ} \mathrm{C}$ under the intermediate and high emissions scenarios, respectively, by the end of the twenty-first century.

Time-series of global mean precipitation from observations and CMIP6 simulations of IITM-ESM and other CMIP6 models are shown in Fig. 1.3b. Global mean precipitation in IITM-ESM and other CMIP6 models show an increase with an increase in temperature, with higher rate of increase in those models with higher levels of warming

Table 1.3 Climate models from the CMIP5 (Taylor et al. 2012) database used in this study. Historical, RCP4.5 and RCP8.5 forcing experiments have been used

\begin{tabular}{l|l}
\hline Model ID & Institute, Country \\
\hline ACCESS1.0 & $\begin{array}{l}\text { Commonwealth Scientific and Industrial Research Organization (CSIRO), Australia and Bureau of Meteorology (BOM), } \\
\text { Australia }\end{array}$ \\
\hline CMCC-CM & Euro-Mediterraneo sui Cambiamenti Climatici, Italy \\
\hline CMCC-CMS & Centre National de Recherches Meteorologiques, Meteo-France, France \\
\hline CNRM-CM5 & Commonwealth Scientific and Industrial Research Organization (CSIRO), Australia \\
\hline CSIRO-Mk3-6-0 & Institute for numerical mathematics, Russia \\
\hline Inm-cm4 & Institute Pierre-Simon Laplace, France \\
\hline IPSL-CM5A-LR & \\
\hline MPI-ESM-LR & Max Planck Institute for Meteorology, Germany \\
\hline MPI-ESM-MR & \\
\hline Total no. models & 10 \\
\hline
\end{tabular}

Only the first available realization is used. (Expansions of acronyms are available online at http://www.ametsoc.org/PubsAcronymList). *All the models from CMIP5/CMIP6 used in the study are interpolated to the resolution of $1 \times 1$ degree 
Table 1.4 Climate models from the CMIP6 (Eyring et al. 2016) database used in this study

\begin{tabular}{l|l}
\hline Model ID & Institute, Country \\
\hline BCC-CESM2-MR & Beijing Climate Center, China Meteorological Administration, China \\
\hline CAMS-CSM1-0 & Chinese Academy of Meteorological Sciences, China \\
\hline CANESM5 & Canadian Centre for Climate Modelling and Analysis, Canada \\
\hline CESM2 & National Science Foundation, Department of Energy, NCAR, USA \\
\hline EC-Earth3 & EC-Earth brings together 27 research institutes from 10 European countries, Europe \\
\hline EC-Earth-Veg & \\
\hline IPSL-CM6A-LR & Institute Pierre-Simon Laplace, France \\
\hline MIROC6 & $\begin{array}{l}\text { Atmosphere and Ocean Research Institute (The University of Tokyo), National Institute for Environmental Studies and } \\
\text { Japan Agency for Marine-Earth Science and Technology, Japan }\end{array}$ \\
\hline MRI-ESM2-0 & Meteorological Research Institute, Japan \\
\hline IITM-ESM & Indian Institute of Tropical Meteorology, India \\
\hline Total no. models & 10 \\
\hline Other specifications are the same as in Table 1.3
\end{tabular}

(Fig. 1.3b). However, regional precipitation patterns can deviate significantly from the global mean, driven by different drivers of climate change like GHGs, aerosols, etc. Precipitation projections from IITM-ESM and CMIP6 models show a gradual increase in global precipitation over the twenty-first century (Fig. 1.3b). Global mean precipitation is projected to increase in IITM-ESM by more than 0.11 and $0.15 \mathrm{~mm} \mathrm{day}^{-1}$ by the end of the twenty-first century (w.r.t 1850-1900) under the SSP2-4.5 and SSP5-8.5 scenarios. The precipitation is also projected to increase over the Indian region in IITM-ESM and CMIP6 models under both SSP5-8.5 and SS2-4.5 scenarios. The far future precipitation increase over the Indian region is $0.51 \mathrm{~mm}$ day $^{-1}$ under SSP5-8.5 and $0.03 \mathrm{~mm} \mathrm{day}^{-1}$ under SS2-4.5 as projected by IITM-ESM.

The AR5 assessment of changes in the ocean indicates that the global ocean will warm in all scenarios. Thermal expansion due to ocean warming and glacier melt have been the dominant contributors to the twentieth-century global mean sea-level rise (Church et al. 2013). The projected changes in global mean sea level due to thermal expansion (thermosteric sea level) are shown in Fig. 1.3c under SSP2-4.5 and SSP5-8.5 scenarios. The global mean thermosteric sea level (TSL) from CMIP6 models shows an increase, especially in the recent decades. The IITM-ESM shows an increase in global mean TSL which is similar to the TSL increase in other CMIP6 models. The global mean TSL rise during the far future (2070-2099) will be about $0.08 \mathrm{~m}-0.17 \mathrm{~m}$ under SSP2-4.5 and $0.11 \mathrm{~m}-0.23 \mathrm{~m}$ under SSP5-8.5, respectively. The TSL projections from
IITM-ESM and other CMIP6 models indicate that the rate of global mean sea-level rise for the twenty-first century will exceed the rate observed during the historical period for SSP2-4.5 and SSP5-8.5 scenarios.

We now assess changes in spatial patterns of surface temperature and precipitation for the historical period (1900-2014) and projections for far future (2070-2099) based on IITM-ESM historical simulation and SSP5-8.5 scenario. Spatial patterns of surface temperature change from IITM-ESM and NASA GISS surface temperature analysis (GISSTEMPV4) w.r.t pre-industrial period are shown in Fig. 1.4. Observations reveal increasing surface temperatures over most of the continental region with fastest-warming over the Arctic. Warming over land is higher as compared to oceans. The anthropogenic warming trend is reasonably well represented in IITM-ESM historical simulation. The model simulates the Arctic amplification and increasing temperature over west-central Asia while warming trends over Europe and east-central Asia are underestimated in the historical simulation. Spatial maps of annual mean surface temperature changes in the far future (20702099) in the SSP5-8.5 scenario show the largest warming over high latitudes, particularly over the Arctic. As the GMST continues to increase, it is very likely that by the end of the twenty-first century most of the global land and ocean areas will be warmer than during the historical period.

The spatial patterns of temperature change over the Indian region are well simulated in IITM-ESM historical simulation. Larger warming pattern is seen over the north and north-west India during the historical period 
(a). Global mean temperature change $\left({ }^{\circ} \mathrm{C}\right.$ relative to $\left.1850-1900\right)$

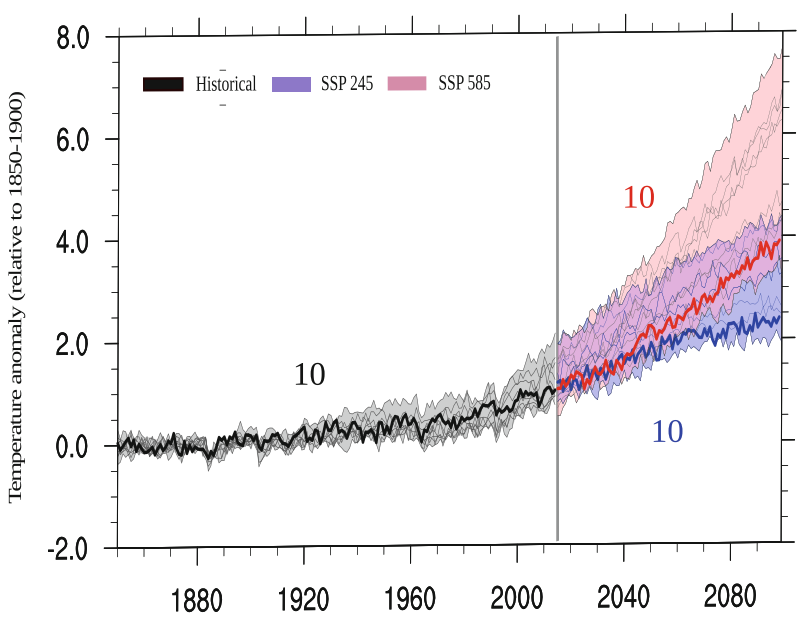

(b). Global mean precipitation change (mm day ${ }^{-1}$ relative to $1850-1900$ )

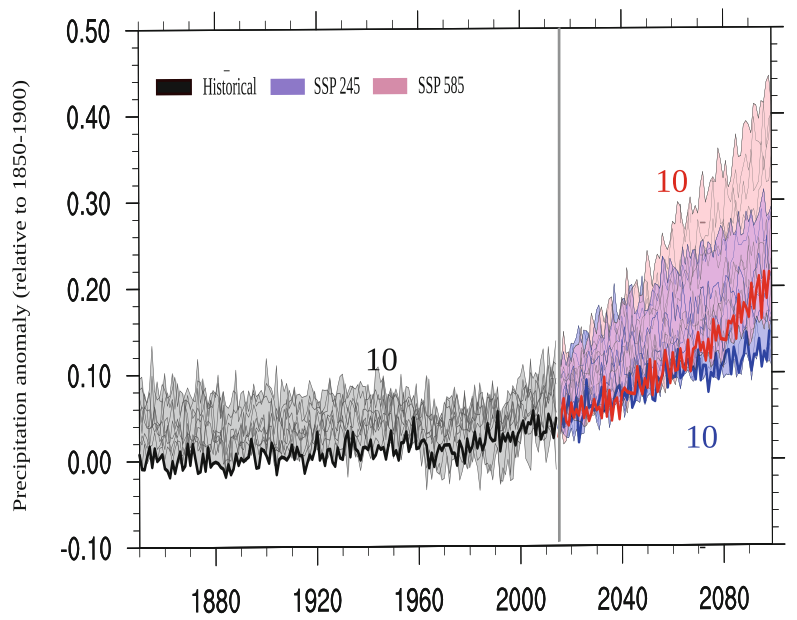

(c). Global mean TSL change (m relative to 1850-1900)

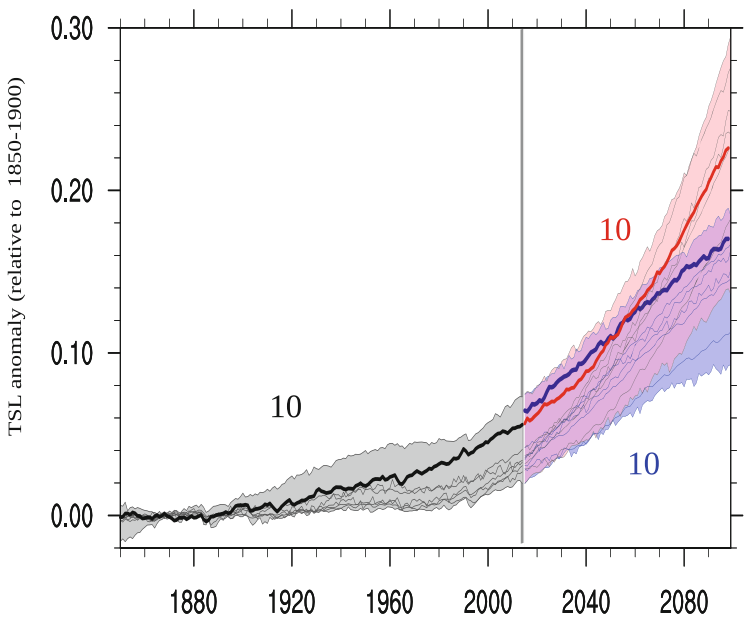

Fig. 1.3 Time series of CMIP6 simulations of the globally averaged annual mean a surface air temperature $\left({ }^{\circ} \mathrm{C}\right)$, b precipitation $\left(\mathrm{mm} \mathrm{day}{ }^{-1}\right)$ and $\mathbf{c}$ thermosteric sea level (TSL; m). Plotted are the anomalies with respect to the pre-industrial baseline $(1850-1900)$ for the historical period (black) and future projections following the SSP2-4.5 (blue) and SSP5-8.5 (red) scenarios. Numbers denote the number of models selected for each variable. Solid lines represent the IITM-ESM simulations and the shading represents the range across the models
(1951-2014), warming exceeding $0.5{ }^{\circ} \mathrm{C}$ over most part of the country. The warming pattern is projected to enhance in the far future, with warming level exceeding $3{ }^{\circ} \mathrm{C}$ as can be seen from the SSP5-8.5 scenario (Fig. 1.4).

Spatial patterns of change in observed and simulated summer monsoon (JJAS) precipitation for the period 19512014 are shown in Fig. 1.5. The precipitation pattern shows large spatial variability over the tropical regions. It is interesting to note that the IITM-ESM captures the observed decrease in summer monsoon precipitation over Central India during 1951-2014. A north-south pattern of monsoon rainfall decrease over Central India and an increase over the equatorial Indian Ocean is seen in the IITM-ESM simulation. The observed weakening of the southwest summer monsoon post-1950s has been attributed to anthropogenic aerosol forcing, regional land use land cover changes as well as rapid warming of the equatorial Indian Ocean SST (Krishnan et al. 2016).

The global mean precipitation is projected to increase with an increase in global mean temperature. Large-scale increase in precipitation is seen over the tropical regions, especially over the monsoon domains and over the Indian landmass in the far future under SSP5-8.5 scenario (Fig. 1.5). Quantitiative estimates of global and regional changes in temperature and precipitation for the near and far future, based on the IITM-ESM and other CMIP6 

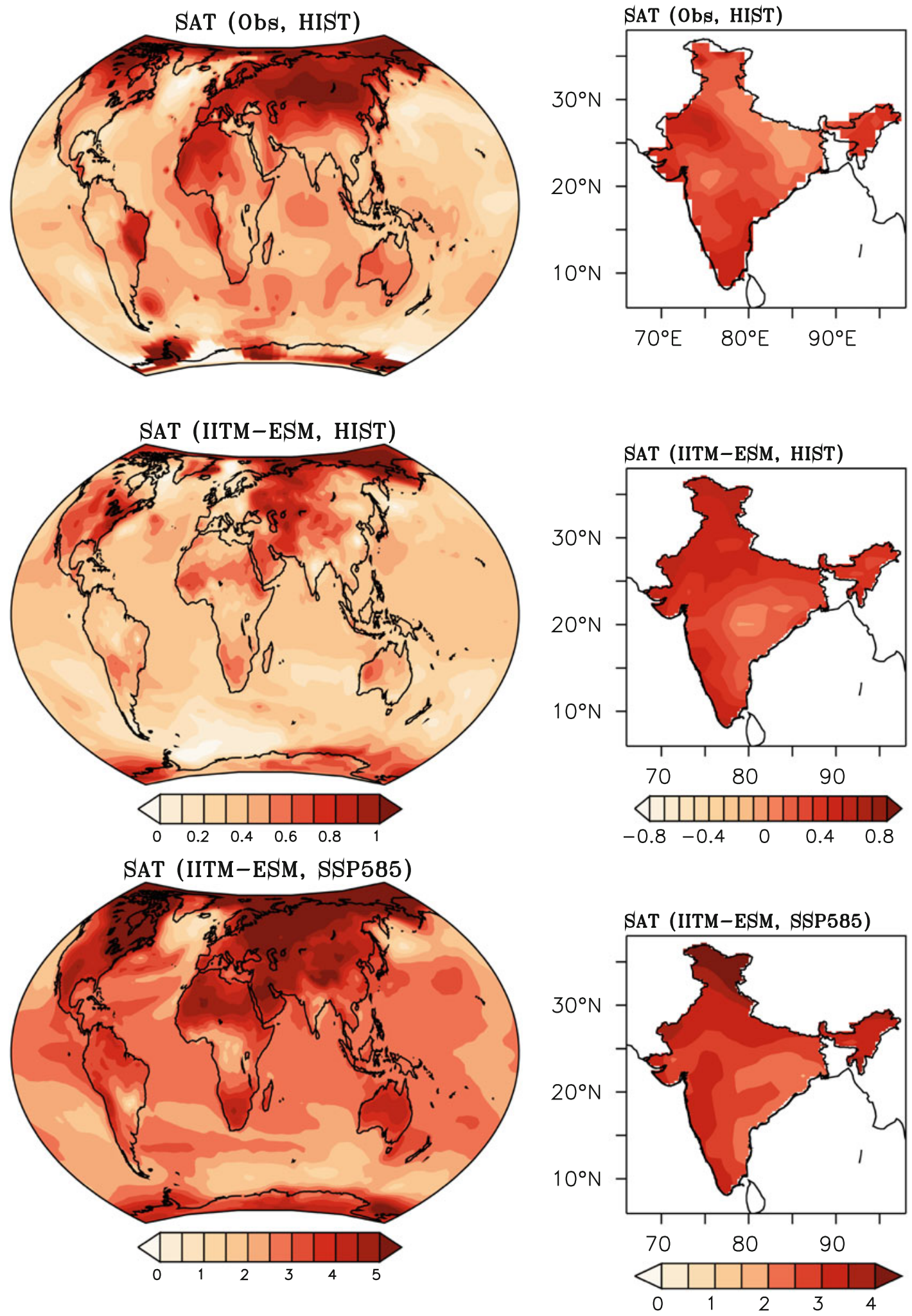

Fig. 1.4 Spatial patterns of change in surface air temperature (SAT; ${ }^{\circ} \mathrm{C}$ ) over the globe in the left-hand column, and over India in the right-hand column. In the top row are plotted the observed changes over the globe based on the Climate Research Unit (CRU) dataset, and over India based on the India Meteorological Department (IMD) dataset. Plots in the middle row are from the IITM-ESM simulations for the historical period, and those in the last row are from the IITM-ESM projections following the SSP5-8.5 scenario. The historical changes in the global maps are shown for the period (1901-2014) and those over India are shown for the period (1951-2014). Changes in the historical period (first and middle rows) are calculated as linear trends and expressed in $\left({ }^{\circ} \mathrm{C}\right.$ per 114 years) for the global maps and $\left({ }^{\circ} \mathrm{C}\right.$ per 64 years) over India. Changes under the SSP5-8.5 scenario (last row) are plotted as the difference in mean temperature between the far future (2070-2099) and pre-industrial (1850-1900) periods 

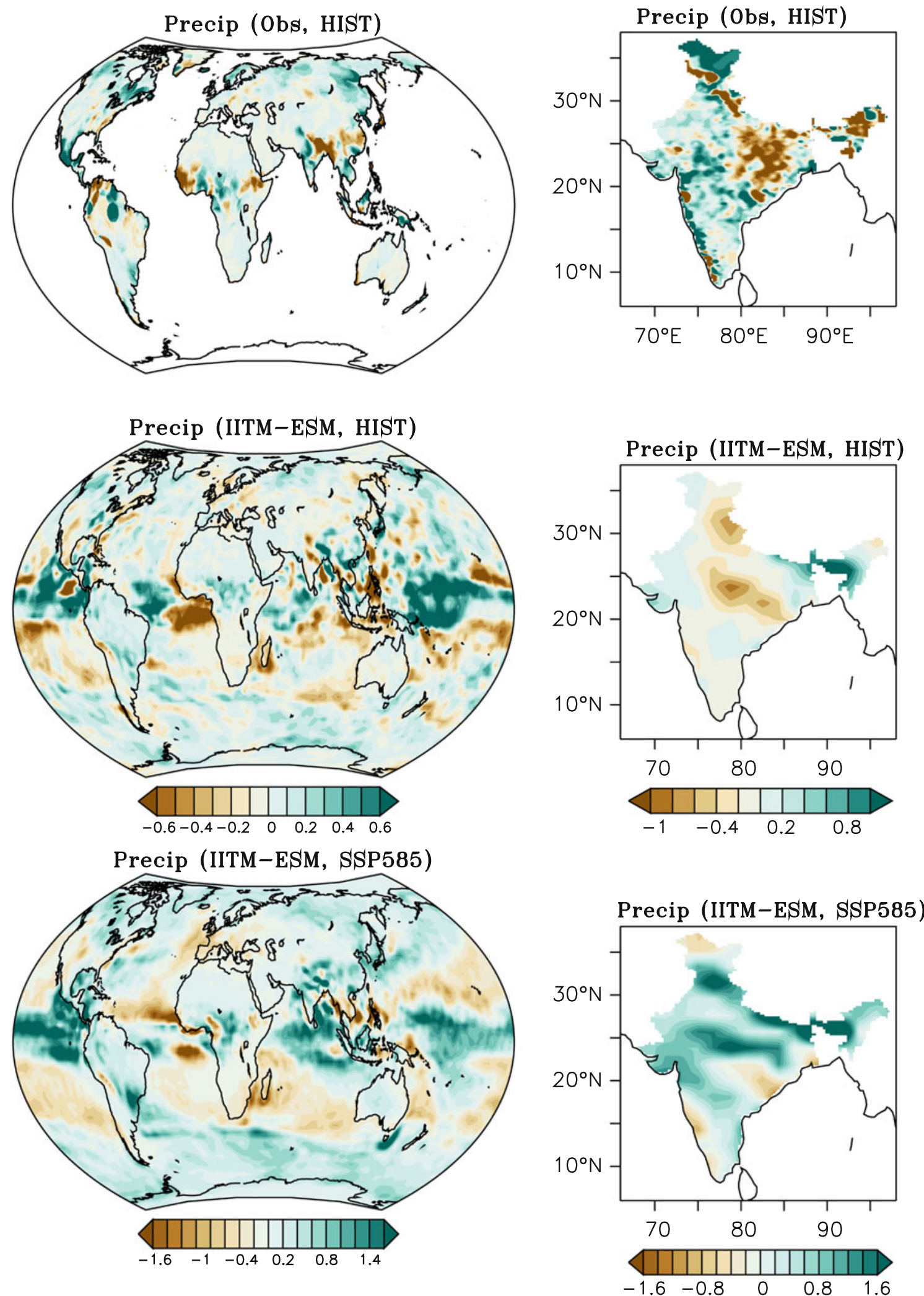

Fig. 1.5 Spatial patterns of change in the June-to-September seasonal precipitation ( $\mathrm{mm} \mathrm{day}^{-1}$ ) over the globe in the left-hand column, and over India in the right-hand column. In the top row are plotted the observed changes for the period (1951-2014) relative to (1900-1930) over the globe based on the CRU dataset, and over India based on the IMD dataset. Plots in the middle row are from the IITM-ESM simulations for the historical period, and the plots in the last row are from the IITM-ESM projections following the SSP5-8.5 scenario. The IITM-ESM simulated changes in the historical period (first and middle rows) are plotted as difference for the period (1951-2014) relative to (1850-1900). Changes under the SSP5-8.5 scenario (last row) are plotted as difference between the far-future (2070-2099) relative to (1850-1900). 


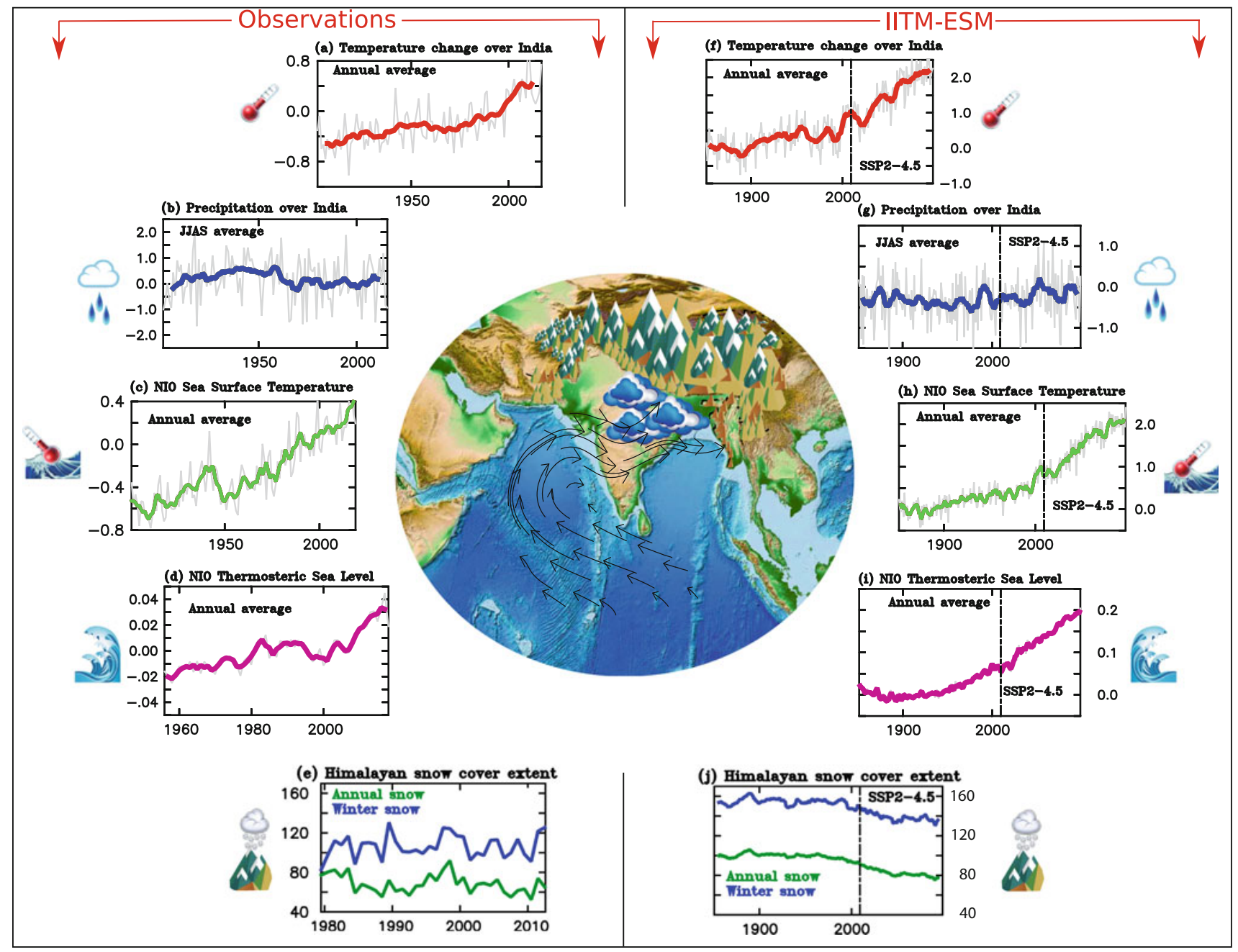

Fig. 1.6 Temporal variation of selected climate variables from observations (panels on the left) and IITM-ESM projections (panels on the right) : Near surface air temperature $\left({ }^{\circ} \mathrm{C}\right)$ over India in (a) and (f); Summer monsoon precipitation ( $\mathrm{mm} /$ day) over Indian land region in (b) and (g); Sea surface temperature of the north Indian Ocean $\left(\mathrm{NIO} ;{ }^{\circ} \mathrm{C}\right)$ in $(\mathbf{c})$ and $(\mathbf{h})$; Thermosteric sea level $(\mathrm{m})$ in the north Indian Ocean in (d) and (i); and Himalayan snow cover extent (x $\left.10000 \mathrm{~km}^{2}\right)$ in (e) and (j). Note that the time-series of all variables, except

models, are tabulated in Table 1.2. Figure 1.6 summarizes the temporal variations in the observed and projected future changes by the IITM-ESM in some key regional climate variables during the twentieth and twenty-first centuries.

\subsubsection{Synthesis of Regional Climate Change}

The surface air temperature over India has risen by about $0.7{ }^{\circ} \mathrm{C}$ during 1901-2018. There are clear signatures of human-induced changes in climate over the Indian region in recent decades, as evidenced by observations, reanalysis
Himalayan snow cover extent, are shown as anomalies w.r.t. a specified baseline. Absolute values of the Himalayan snow cover extent are shown in (e) and (j). The IITM-ESM projections cover the period from 1850 to 2100 , with the future projections based on the SSP2-4.5 scenario. All anomalies in the IITM-ESM projections are computed w.r.t. the pre-industrial baseline (1850-1900) and anomalies in observed changes (left panels) are w.r.t. the recent period (1976-2005)

datasets and climate model simulations. These changes are on account of anthropogenic GHG and aerosol forcings, and changes in land use and land cover (e.g. Krishnan and Ramanathan 2002; Dileepkumar et al. 2018).

Future projections of regional climate, under different climate change scenarios, indicate robust changes in the mean, variability and extremes of several key climatic parameters over the Indian subcontinent and adjoining areas, e.g. land temperature and precipitation, monsoons, Indian Ocean temperature and sea level, tropical cyclones, Himalayan cryosphere, etc.

A synthesis of the assessed past and projected changes in key climate variables pertinent to the Indian region is 
presented in Table 1.5 and also illustrated in Fig. 1.6 (IITM-ESM). The qualifiers to express certainty in the assessments are presented in Box 1.4.

\section{Box 1.4: Qualifiers to Express Certainty in Assessment Findings}

Two qualifiers have been used in this assessment report to express the degree of certainty in key findings.

- Confidence is a qualitative expert judgement by the authors based on an evaluation of available information in terms of 1 . The amount, quality and consistency of evidence and 2. Agreement within the surveyed literature.

\section{Confidence levels (based on IPCC):}

- Very high: Robust evidence, high agreement.

- High: Robust evidence, medium agreement; Medium evidence, high agreement.

- Medium: Medium evidence, medium agreement.

- Low: Limited evidence, low agreement.

\section{Broad criteria adopted in this Report to gauge} 'evidence':

- $>3$ scientific papers: Robust evidence;

- 2-3 scientific papers: Medium evidence;

- 2 scientific papers: Limited evidence;

- 1 scientific paper: Insufficient evidence.

\section{Broad criteria adopted in this Report to gauge} 'agreement':

- $>70 \%$ agreement in surveyed literature: High agreement;

- $50-70 \%$ agreement in surveyed literature: Medium agreement;

- $30-50 \%$ agreement in surveyed literature: Low agreement;

- $<30 \%$ agreement in surveyed literature: No agreement.

Confidence cannot be interpreted statistically.

- Likelihood is a quantitative measure of uncertainty based on the probability of an outcome or result based on a statistical analysis of observational data or modelling outcomes or on the authors' expert judgement.

\section{Likelihood levels (adopted from IPCC):}

- Virtually certain: $99-100 \%$ probability;

- Very likely: $90-100 \%$;

- Likely: 66-100\%;

- About as likely as not: $33-66 \%$;

- Unlikely: 0-33\%;

- Very unlikely: 0-10\%;

- Exceptionally unlikely: 0-1\%.

See for more details: Mastrandrea, M. D., C. B. Field, T. F. Stocker, O. Edenhofer, K. L. Ebi, D. J. Frame, H. Held, E. Kriegler, K. J. Mach, P. R. Matschoss, G.-K. Plattner, G. W. Yohe and F. W. Zwiers 2010: Guidance Note for Lead Authors of the IPCC Fifth Assessment Report on Consistent Treatment of Uncertainties, Intergovernmental Panel on Climate Change (IPCC), Geneva, Switzerland, 4 pp.

\subsection{Scope of the Report}

This report provides a detailed overview and synthesis of the published scientific literature on climate change over India and adjoining regions. The objectives are to provide a state-of-the-art assessment of how and why India's climate is changing, changes that are projected for the future, uncertainties and knowledge gaps, and identification of areas that require greater research.

The scope of this report is the physical science basis of climate change with a focus on regional climate drivers specific to the Indian land area and the surrounding ocean. It is a region-focused analogue of the global scale assessment by Working Group I of the Intergovernmental Panel on Climate Change.

This report will be useful to advance public awareness of India's changing climate and to inform mitigation and adaptation decision making. While it is meant to be policy relevant, this report is not intended to be policy prescriptive.

This report is organized as follows: Chapters 2 and 3 focus on observed and projected trends in the mean and extremes of temperature and precipitation. Chapters 4 and 5 quantify the spatial and temporal variations in GHG fluxes and concentrations, and climate forcing due to anthropogenic aerosol emissions and trace gases over India. Chapter 6 discusses the observed and projected changes in 
Table 1.5 Synthesis of the assessed past and projected changes in key climate variables pertinent to the Indian region

\section{Warming over India and the Indian Ocean (Chaps. 2, 10)}

The annual mean near-surface air temperature over India has warmed by around $0.7{ }^{\circ} \mathrm{C}$ during $1901-2018$ (Srivastava et al. 2019), with the post-1950 trends attributable largely to anthropogenic activities (Dileepkumar et al. 2018) (High confidence). Atmospheric moisture content over the Indian region has also risen during this period (Krishnan et al. 2016; Mukhopadhyay et al. 2017; Mukherjee et al. 2018) (High confidence). The mean temperature rise over India by the end of the twenty-first century is projected to be in the range of $2.4-4.4{ }^{\circ} \mathrm{C}$ across greenhouse gas warming scenarios relative to the average temperature over 1976-2005.

The Indian Ocean has also experienced significant warming in recent decades in association with anthropogenic radiative forcing (Du and Xie 2008), as well as ocean-atmosphere coupled feedbacks arising from long-term changes in monsoonal wind patterns (Swapna et al. 2014) (High confidence). Sea surface temperature (SST) in the tropical Indian Ocean has risen by $1{ }^{\circ} \mathrm{C}$ on average over $1951-2015$ and is projected to increase further during the twenty-first century.

\section{Monsoon Precipitation (Chap. 3)}

Warming due to increasing concentration of atmospheric GHGs and moisture content is generally expected to strengthen the Indian monsoon. Yet, the observational records show that there has been a declining trend in summer monsoon precipitation since 1950 (Kulkarni 2012), with particularly notable decreases in parts of the Indo-Gangetic plains and the Western Ghats (Krishnan et al. 2013; Roxy et al. 2015). Climate modelling studies suggest that the observed changes have resulted in response to the radiative effects of the northern hemispheric $(\mathrm{NH})$ anthropogenic aerosols and regional LULC, which have more than offset the precipitation enhancing tendency of GHG warming in the past 6-7 decades (e.g. Bollasina et al. 2011; Krishnan et al. 2016; Sanap et al. 2015; Undorf et al. 2018) (Medium confidence).

In contrast, the frequency of localized heavy precipitation occurrences has risen significantly over Central India in the past 6-7 decades (Roxy et al. 2017; Mukherjee et al. 2018) (High confidence).

With anticipated reductions in NH aerosol emissions, future changes in the monsoon precipitation are expected to be prominently constrained by the effects of GHG warming. With the resultant increase in temperature and atmospheric moisture, climate models project a considerable rise in the mean, extremes and interannual variability of monsoon precipitation by the end of the century (Kitoh 2017).

\section{Droughts and Floods (Chap. 6)}

India has witnessed a higher frequency of droughts and expansion of drought-affected areas since 1950. While climate models project an enhancement of mean monsoon rainfall in the future, they concurrently project an increase in the occurrence, severity and area under drought. These changes are linked to increased variability of monsoon precipitation, and increase in water vapour demand in a warmer atmosphere that would tend to decrease soil moisture content (Menon et al. 2013; Scheff and Frierson 2014; Jayasankar et al. 2015; Sharmila et al. 2015; Krishnan et al. 2016; Preethi et al. 2019) (High confidence).

Flooding events over India have also increased since 1950, in part due to enhanced occurrence of localized, short-duration intense rainfall events and flooding occurrences due to intense rainfall are projected to increase in the future (Hirabayashi et al. 2013; Ali and Mishra 2018; Lutz et al. 2019) (High confidence). Higher rates of glacier and snowmelt in a warming world would enhance stream flow and compound flood risk over the Himalayan river basins. The Indus, Ganga and Brahmaputra basins are considered particularly at risk of enhanced flooding in the future in the absence of additional adaptation and risk mitigation measures (Lutz et al. 2014).

\section{Sea-level rise in the North Indian Ocean (Chap. 9)}

Sea-level rise is intimately related to thermal expansion due to rising ocean SST and heat content, and the melting of glaciers that add water to the world's oceans. Rates of sea-level variations differ from region to region.

The North Indian Ocean (NIO) rose at a rate of $3.3 \mathrm{~mm} \mathrm{year}^{-1}$ during 1993-2017, similar to the global mean (Swapna et al. 2017). While thermal expansion (thermosteric) has dominated sea-level rise in the NIO) (High confidence), the major contribution to global mean sea-level rise is from glacier melt (IPCC AR5).

The thermosteric sea-level rise of the NIO during the recent 3-4 decades is closely linked to the weakening trend of summer monsoon winds and the associated slow down of heat transport out of the NIO (Swapna et al. 2017). Future changes in the strength of monsoon winds have implications on the NIO sea-level variations.

\section{Tropical Cyclonic Storms (Chap. 8)}

The intensity of tropical cyclones (TC) is closely linked to ocean SST and heat content, with regional differences in their relationships.

The frequency of very severe cyclonic storms (VSCS) over the NIO during the post-monsoon season has significantly increased in the past two decades, despite an overall reduction in the annual TC activity (High confidence). With continued global warming, the activity of VSCS over the NIO is projected to further increase during the twenty-first century.

\section{Himalayan Cryosphere (Chap. 11)}

The Hindukush Himalayas (HKH) underwent rapid warming at a rate of about $0.2^{\circ} \mathrm{C}$ per decade during the last 6-7 decades) (High confidence). Higher elevations of the Tibetan Plateau $(>4 \mathrm{~km})$ experienced even stronger warming in a phenomenon alluded to as Elevation Dependent Warming (Liu et al. 2009; Krishnan et al. 2019b) (High confidence). With continued global warming, the temperature in the $\mathrm{HKH}$ is projected to rise substantially during the twenty-first century.

The HKH experienced a significant decline in snowfall (Ren et al. 2015; You et al. 2015) and glacial area (Kulkarni and Karyakarte 2014; Wester et al. 2019) in the last 4-5 decades (Medium confidence). With continuing warming, climate models project a continuing decline in snowfall over the HKH during the 21st century, but with wide inter-model spread. In contrast, parts of the Karakoram Himalayas have experienced increase in wintertime frozen precipitation in the recent decades, in association with enhanced amplitude variations of Western Disturbances (Kapnick et al. 2014; Kääb et al. 2015; Krishnan et al. 2019b). 
the characteristics of floods and droughts in India associated with changes in precipitation. Chapter 7 discusses synoptic scale systems including trends in monsoon depressions and western disturbances. Chapters 8, 9, and 10 discuss the changes in the frequency and intensity of extreme storms, trends and projections of sea level rise and its variability along the Indian coast, and historical changes and projections of warming of the Indian Ocean and changes in its heat content. Chapter 11 discusses observed and projected changes in temperature, snowfall, and glaciers in the Hindu Kush Himalayas. Chapter 12 closes with a brief outline of the potential impacts of climate change pertinent to India and policies that may help advance adaption and mitigation efforts.

Comprehensive assessments of the societal and sectoral impacts of regional climate change will require targeted research and are beyond the scope of this report.

\section{References}

Allen, M.R., O.P. Dube, W. Solecki, F. Aragón-Durand, W. Cramer, S. Humphreys, M. Kainuma, J. Kala, N. Mahowald, Y. Mulugetta, R. Perez, M. Wairiu, and K. Zickfeld, 2018: Framing and Context. In: Global Warming of $1.5^{\circ} \mathrm{C}$. An IPCC Special Report on the impacts of global warming of $1.5^{\circ} \mathrm{C}$ above pre-industrial levels and related global GHG emissions pathways, in the context of strengthening the global response to the threat of climate change, sustainable development, and efforts to eradicate poverty [Masson-Delmotte, V., P. Zhai, H.-O. Pörtner, D. Roberts, J. Skea, P.R. Shukla, A. Pirani, W. Moufouma-Okia, C. Péan, R. Pidcock, S. Connors, J.B. R. Matthews, Y. Chen, X. Zhou, M.I. Gomis, E. Lonnoy, T. Maycock, M. Tignor, and T. Waterfield (eds.)]

Ali H, Mishra V (2018) Increase in subdaily precipitation extremes in india under 1.5 and $2.0^{\circ} \mathrm{C}$ warming worlds. Geophys Res Lett 45 (14):6972-6982

Bindoff NL, Stott PA, AchutaRao KM, Allen MR, Gillett N, Gutzler D, Hansingo K, Hegerl G, Hu Y, Jain S, Mokhov II, Overland J, Perlwitz J, Sebbari R, Zhang X (2013) Detection and attribution of climate change: from global to regional. In: Stocker TF, Qin D, Plattner G-K, Tignor M, Allen SK, Boschung J, Nauels A, Xia Y, Bex V, Midgley PM (eds) Climate change 2013: the physical science basis. Contribution of working group I to the fifth assessment report of the intergovernmental panel on climate change. Cambridge University Press, Cambridge

Bollasina MA, Ming Y, Ramaswamy V (2011) Anthropogenic aerosols and the weakening of the South Asian summer monsoon. Science 334:502-505

Boos WR, Kuang Z (2010) Dominant control of the South Asian monsoon by orographic insulation versus plateau heating. Nature 463:218-222. https://doi.org/10.1038/nature08707

Burkett VR, Suarez AG, Bindi M, Conde C, Mukerji R, Prather MJ, St. Clair AL, Yohe GW (2014) Point of departure. In: Field CB, Barros VR, Dokken DJ, Mach KJ, Mastrandrea MD, Bilir TE, Chatterjee M, Ebi KL, Estrada YO, Genova RC, Girma B, Kissel ES, Levy AN, MacCracken S, Mastrandrea PR, White LL (eds) Climate change 2014: impacts, adaptation, and vulnerability. Part A: global and sectoral aspects. Contribution of working group II to the fifth assessment report of the intergovernmental panel on climate change. Cambridge University Press, Cambridge, pp 169194

Calel R, Stainforth DA (2017) On the physics of three integrated assessment models. Bull Am Meteorol Soc 98:1199-1216. https:// doi.org/10.1175/BAMS-D-16-0034.1

Choudhury AD, Krishnan R (2011) Dynamical response of the South Asian Monsoon trough to latent heating from stratiform and convective precipitation. J Atmos Sci 68(6):1347-1363. https://doi. org/10.1175/2011JAS3705.1

Choudhury AD, Krishnan R, Ramarao MVS, Vellore R, Singh M, Mapes B (2018) A phenomenological paradigm for midtropospheric cyclogenesis in the Indian summer monsoon. J Atmos Sci 75 (9):2931-2954. https://doi.org/10.1175/JAS-D-17-0356.1

Church JA, Clark PU, Cazenave A, Gregory JM, Jevrejeva S, Levermann A, Merrifield MA, Milne GA, Nerem RS, Nunn PD, Payne AJ, Pfeffer WT, Stammer D, Unnikrishnan AS (2013) Sea level change. In: Stocker TF, Qin D, Plattner G-K, Tignor M, Allen SK, Boschung J, Nauels A, Xia Y, Bex V, Midgley PM (eds) Climate change 2013: the physical science basis. Contribution of working group I to the fifth assessment report of the intergovernmental panel on climate change. Cambridge University Press, Cambridge

Collins M, Knutti R, Arblaster J, Dufresne J-L, Fichefet T, Friedlingstein P, Gao X, Gutowski WJ, Johns T, Krinner G, Shongwe M, Tebaldi C, Weaver AJ, Wehner M (2013) Long-term climate change: projections, commitments and irreversibility. In: Stocker TF, Qin D, Plattner G-K, Tignor M, Allen SK, Boschung J, Nauels A, Xia Y, Bex V, Midgley PM (eds) Climate change 2013: the physical science basis. Contribution of working group I to the fifth assessment report of the intergovernmental panel on climate change. Cambridge University Press, Cambridge

Cowtan K, Hausfather Z, Hawkins E, Jacobs P, Mann ME, Miller SK, Steinman BA, Stolpe MB, Way RG (2015) Robust comparison of climate models with observations using blended land air and ocean sea surface temperatures. Geophys Res Lett 42:6526-6534. https:// doi.org/10.1002/2015GL064888

Dileepkumar R, AchutaRao K, Arulalan T (2018) Human influence on sub-regional surface air temperature change over India. Sci Rep 8 (1):8967. https://doi.org/10.1038/s41598-018-27185-8

Dimri AP, Niyogi D, Barros AP, Ridley J, Mohanty UC, Yasunari T, Sikka DR (2015) Western disturbances: a review. Rev Geophys. https://doi.org/10.1002/2014RG000460

Du Y, Xie S-P (2008) Role of atmospheric adjustments in the tropical Indian Ocean warming during the 20th century in climate models. Geophys Res Lett 35:L08712. https://doi.org/10.1029/2008GL033631

Eyring V, Bony S, Meehl G, Senior C, Stevens B, Stouffer R, Taylor K (2016) Overview of the coupled model intercomparison project phase 6 (CMIP6) experimental design and organization. Geosci Model Dev 9(5):1937-1958. https://doi.org/10.5194/gmd-9-19372016

Flato G, Marotzke J, Abiodun B, Braconnot P, Chou SC, Collins W, Cox P, Driouech F, Emori S, Eyring V, Forest C, Gleckler P, Guilyardi E, Jakob C, Kattsov V, Reason C, Rummukainen M (2013) Evaluation of climate models. In: Stocker TF, Qin D, Plattner G-K, Tignor M, Allen SK, Boschung J, Nauels A, Xia Y, Bex V, Midgley PM (eds) Climate change 2013: the physical science basis. Contribution of working group I to the fifth assessment report of the intergovernmental panel on climate change. Cambridge University Press, Cambridge

Gadgil S (2003) The Indian monsoon and its variability. Annu Rev Earth Planet Sci 31:429-467

Hartmann DL, Klein Tank AMG, Rusticucci M, Alexander LV, Brönnimann S, Charabi Y, Dentener FJ, Dlugokencky EJ, Easterling DR, Kaplan A, Soden BJ, Thorne PW, Wild M, Zhai PM (2013) Observations: atmosphere and surface. In: Stocker TF, 
Qin D, Plattner G-K, Tignor M, Allen SK, Boschung J, Nauels A, Xia Y, Bex V, Midgley PM (eds) Climate change 2013: the physical science basis. Contribution of working group I to the fifth assessment report of the intergovernmental panel on climate change. Cambridge University Press, Cambridge

Haustein K, Allen MR, Forster PM, Otto FEL, Mitchell DM, Matthews HD, Frame DJ (2017) A real-time global warming index. Sci Rep 7:15417. https://doi.org/10.1038/s41598-017-14828-5

Hirabayashi Y, Mahendran R, Koirala S et al (2013) Global flood risk under climate change. Nat Clim Change 3:816-821. https://doi.org/ 10.1038/nclimate1911

Houze RA (1997) Stratiform precipitation in regions of convection: a meteorological paradox? Bull Am Meteor Soc 78(10):2179-2196. https://doi.org/10.1175/1520-0477(1997)078\%3c2179:SPIROC\% 3e2.0.CO;2

Houze RA, Wilton DC, Smull BF (2007) Monsoon convection in the Himalayan region as seen by the TRMM precipitation radar. Quart J R Meteorol Soc. https://doi.org/10.1002/qj.106

Hunt KMR, Turner AG, Shaffrey LC (2018) The evolution, seasonality and impacts of western disturbances. R Meteorol Soc, Q.J. https:// doi.org/10.1002/qj.3200

Jayasankar CB, Surendran S, Rajendran K (2015) Robust signals of future projections of Indian summer monsoon rainfall by IPCC AR5 climate models: role of seasonal cycle and interannual variability. Geophys Res Lett 42(9):3513-3520. https://doi.org/10.1002/ 2015GL063659

Kääb A, Treichler D, Nuth C, Berthier E (2015) Brief communication: contending estimates of 2003-2008 glacier mass balance over the Pamir-Karakoram-Himalaya. Cryosphere 9(2):557-564. https:// doi.org/10.5194/tc-9-557-2015

Kapnick SB, Delworth TL, Ashfaq M, Malyshev S, Milly PCD (2014) Snowfall less sensitive to warming in Karakoram than in Himalayas due to a unique seasonal cycle. Nat Geosci 7:834-840

Kirtman B et al (2013) Near-term climate change: projections and predictability. In: Stocker TF, Qin D, Plattner G-K, Tignor M, Allen SK, Boschung J, Nauels A, Xia Y, Bex V, Midgley PM (eds) Climate change 2013: the physical science basis. Contribution of working group I to the fifth assessment report of the intergovernmental panel on climate change. Cambridge University Press, Cambridge, pp 953-1028

Kitoh A (2017) The Asian monsoon and its future change in climate models: a review. J Meteorol Soc Jpn. Ser. II 95(1):7-33. https:// doi.org/10.2151/jmsj.2017-002

Konwar M, Das SK, Deshpande SM, Chakravarty K, Goswami BN (2014) Microphysics of clouds and rain over the Western Ghat. J Geophys Res Atmos 119(10):6140-6159. https://doi.org/10.1002/ 2014JD021606

Krishnamurti TN, Surgi N (1987) Observational aspects of summer monsoon. In: Chang C-P, Krishnamurti TN (eds) Chapter in book Monsoon meteorology. Oxford University Press, Oxford, pp 3-25

Krishnan R, Ramanathan V (2002) Evidence of surface cooling from absorbing aerosols. Geophys Res Lett 29:2002GL014687, 54 (1-4)

Krishnan R, Sabin TP, Ayantika DC, Kitoh A, Sugi M, Murakami H, Turner AG, Slingo JM, Rajendran K (2013) Will the South Asian monsoon overturning circulation stabilize any further? Clim Dyn 40:187-211

Krishnan R, Sabin TP, Vellore R, Mujumdar M, Sanjay J, Goswami BN, Hourdin F, Dufresne J-L, Terray P (2016) Deciphering the desiccation trend of the South Asian monsoon hydroclimate in a warming world. Clim Dyn 47:1007-1027. https://doi.org/10.1007/s00382-015-2886-5

Krishnan R, Sabin TP, Madhura RK, Vellore RK, Mujumdar M, Sanjay J, Nayak S, Rajeevan M (2019a) Non-monsoonal precipitation response over the western Himalayas to climate change. Clim Dyn 52:4091-4109
Krishnan R et al (2019b) Unravelling climate change in the Hindu Kush Himalaya: rapid warming in the mountains and increasing extremes. In: Wester P, Mishra A, Mukherji A, Shrestha A (eds) The Hindu Kush himalaya assessment. Springer, Cham

Kulkarni A (2012) Weakening of Indian summer monsoon rainfall in warming environment. Theoret Appl Climatol 109:447-459

Kulkarni AV, Karyakarte Y (2014) Observed changes in Himalayan glaciers. Curr Sci 106(2):237-244

Liu X, Cheng Z, Yan L et al (2009) Elevation dependency of recent and future minimum surface air temperature trends in the Tibetan Plateau and its surroundings Glob. Planet Change 68:164-174

Lutz AF, Immerzeel WW, Shrestha AB, Bierkens MFP (2014) Consistent increase in High Asia's runoff due to increasing glacier melt and precipitation. Nat Clim Chang 4:587-592. https://doi.org/ 10.1038/nclimate2237

Lutz AF, terMaat HW, Wijngaard RR et al (2019) South Asian river basins in a $1.5^{\circ} \mathrm{C}$ warmer world. Reg Environ Chang 19:833-847. https://doi.org/10.1007/s10113-018-1433-4

Marcott SA, Shakun JD, Clark PU, Mix AC (2013) A reconstruction of regional and global temperature for the past 11,300 years. Science 339(6124):1198-1201. https://doi.org/10.1126/science.1228026

Meehl GA, Boer GJ, Covey C, Latif M, Stouffer RJ (2000) The coupled model intercomparison project (CMIP). Bull Amer Meteor Soc 81:313-318

Meehl GA, Hibbard KA (2007) A strategy for climate change stabilization experiments with AOGCMS and ESMS. WCRP Informal Rep. 3/2007, ICPO Publ. 112, IGBP Rep. 57, 35 pp

Menon A, Levermann A, Schewe J (2013) Enhanced future variability during India's rainy season. GRL 40:3242-3247

Mukherjee S, Aadhar S, Stone D, Mishra V (2018) Increase in extreme precipitation events under anthropogenic warming in India. Weather Clim Extremes 20:45-53

Mukhopadhyay P, Jaswal A, Deshpande M (2017) In: Rajeevan M, Nayak S (eds) Observed climate variability and change over the Indian region. Springer, Berlin, pp 129-144

Myhre G, Shindell D, Bréon F-M, Collins W, Fuglestvedt J, Huang J, Koch D, Lamarque J-F, Lee D, Mendoza B, Nakajima T, Robock A, Stephens G, Takemura T, Zhang H (2013) Anthropogenic and natural radiative forcing. In: Stocker TF, Qin D, Plattner G-K, Tignor M, Allen SK, Boschung J, Nauels A, Xia Y, Bex V, Midgley PM (eds) Climate change 2013: the physical science basis. Contribution of working group I to the fifth assessment report of the intergovernmental panel on climate change. Cambridge University Press, Cambridge

Nair VS, Babu SS, Manoj MR, Moorthy KK, Chin M (2016) Direct radiative effects of aerosols over South Asia from observations and modeling. Clim Dyn 49:1411-1428. https://doi.org/10.1007/ s00382-016-3384-0

O'Neill BC et al (2017) The roads ahead: narratives for shared socioeconomic pathways describing world futures in the $21 \mathrm{st}$ century. Glob Environ Change 42:169-180. https://doi.org/10.1016/ j.gloenvcha.2015.01.004

Otto FEL, Frame DJ, Otto A, Allen MR (2015) Embracing uncertainty in climate change policy. Nat Clim Change 5:1-5. https://doi.org/ $10.1038 /$ nclimate 2716

Pant GB, Parthasarathy B (1981) Some aspects of an association between the Southern Oscillation and Indian summer monsoon. Arch Meteor Geophys Biokl B29:245-252

Rajeevan M, Unnikrishnan CK, Bhate J, Niranjan Kumar K, Sreekala PP (2012) Northeast monsoon over India. Meteorol Appl 19:226-236

Rajendran K, Kitoh A (2008) Indian summer monsoon in future climate projection by a super high-resolution global model. Curr Sci 95 (11):1560-1569 
Rajeevan M, Gadgil S, Bhate J (2010) Active and break spells of the Indian summer monsoon. J Earth Sys Sci 119:229-248

Rao YP (1976) Southwest Monsoons. Meteor Monogr 1. India Meteorological Department, pp 1-367

Ren YY, Parker D, Ren GY, Dunn R (2015) Tempo-spatial characteristics of sub-daily temperature trends in mainland China. Clim Dyn 46(9-10):2737-2748. https://doi.org/10.1007/s00382-015-2726-7

Richardson M, Cowtan K, Millar RJ (2018) Global temperature definition affects achievement of long-term climate goals. Environ Res Lett 13(5):054004. https://doi.org/10.1088/1748-9326/aab305

Romatschke U, Houze RA (2011) Characteristics of precipitating convective systems in the South Asian Monsoon. J Hydrometeorol 12(1):3-26. https://doi.org/10.1175/2010JHM1289.1

Roxy MK, Ghosh S, Pathak A, Athulya R, Mujumdar M, Raghu M, Pascal T, Rajeevan M (2017) A threefold rise in widespread extreme rain events over central India. Nat Commun 8:708

Roxy MK, Kapoor R, Terray P, Murtugudde R, Ashok K, Goswami BN (2015) Drying of Indian subcontinent by rapid Indian Ocean warming and a weakening land-sea thermal gradient. Nat Commun 6(7423)

Sabin TP, Krishnan R, Ghattas J, Denvil S, Dufresne J-L, Hourdin F, Pascal T (2013) High resolution simulation of the South Asian monsoon using a variable resolution global climate model. Clim Dyn 41(1):173-194. https://doi.org/10.1007/s00382-012-1658-8

Sanap SD, Pandithurai G, Manoj MG (2015) On the response of Indian summer monsoon to aerosol forcing in CMIP5 model simulations. Clim Dyn. https://doi.org/10.1007/s00382-015-2516-2

Scheff J, Frierson DMW (2014) Scaling potential evapotranspiration with greenhouse warming. J Clim 27:1539-1558. https://doi.org/10. 1175/JCLI-D-13-00233.1

Schneider T, Bischoff T, Huag GH (2014) Migrations and dynamics of the intertropical convergence zone. Nature 45. DOI:10.1038/nature13636

Sharmila S, Joseph S, Sahai AK, Abhilash S, Chattopadhyay R (2015) Future projection of Indian summer monsoon variability under climate change scenario: an assessment from CMIP5 climate models. Global Planet Change 124:62-78. https://doi.org/10.1016/ j.gloplacha.2014.11.004

Shige S, Nakano Y, Yamamoto MK (2017) Role of orography, diurnal cycle, and intraseasonal oscillation in summer monsoon rainfall over the Western Ghats and Myanmar Coast. J Clim 30(23):93659381. https://doi.org/10.1175/JCLI-D-16-0858.1

Sinha A, Kathayat G, Cheng H, Breitenbach SFM, Berkelhammer M, Mudelsee M, Biswas J, Edwards RL (2015) Trends and oscillations in the Indian summer monsoon rainfall over the last two millennia. Nat Commun. https://doi.org/10.1038/ncomms7309

Sperber KR, Annamalai H, Kang I-S, Kitoh A, Moise A, Turner A et al (2013) The Asian summer monsoon: an intercomparison of CMIP5 vs. CMIP3 simulations of the late 20th century. Clim Dyn 41:27112744. https://doi.org/10.1007/s00382-012-1607-6

Srivastava AK, Revadekar JV, Rajeevan M (2019) Regional climates: Asia: South Asia (in "State of the climate in 2018"). Bull Am Meteor Soc 100(9):S236-S240. https://doi.org/10.1175/ 2019BAMSStateoftheClimate.1

Stano G, Krishnamurti TN, Vijaya Kumar TSV, Chakraborty A (2002) Hydrometeor structure of a composite monsoon depression using the TRMM radar. Tellus A 54:370-381. https://doi.org/ 10.1034/j.1600-0870.2002.01330.x

Stocker TF, Qin D, Plattner G-K, Alexander LV, Allen SK, Bindoff NL, Bréon F-M, Church JA, Cubasch U, Emori S, Forster P,
Friedlingstein P, Gillett N, Gregory JM, Hartmann DL, Jansen E, Kirtman B, Knutti R, Krishna Kumar K, Lemke P, Marotzke J, Masson-Delmotte V, Meehl GA, Mokhov II, Piao S, Ramaswamy V, Randall D, Rhein M, Rojas M, Sabine C, Shindell D, Talley LD, Vaughan DG, Xie S-P (2013) Technical summary. In: Stocker TF, Qin D, Plattner G-K, Tignor M, Allen SK, Boschung J, Nauels A, Xia Y, Bex V, Midgley PM (eds) Climate change 2013: the physical science basis. Contribution of working group I to the fifth assessment report of the intergovernmental panel on climate. Cambridge University Press, Cambridge

Swapna P, Jyoti J, Krishnan R, Sandeep N, Griffies SM (2017) Multidecadal weakening of Indian summer monsoon circulation induces an increasing Northern Indian Ocean Sea Level. Geophys Res Lett 44. DOI:10.1002/2017GL074706

Swapna P, Krishnan R, Sandeep N, Prajeesh AG, Ayantika DC, Manmeet $S$ et al (2018) Long-term climate simulations using the IITM earth system Model (IITM-ESMv2) with focus on the South Asian Monsoon. J Adv Model Earth Syst 10. DOI:10.1029/2017MS001262

Swapna P, Krishnan R, Wallace JM (2014) Indian Ocean and monsoon coupled interactions in a warming environment. Clim Dyn 42(910):2439-2454. https://doi.org/10.1007/s00382-013-1787-8

Swapna P, Roxy MK, Aparna K, Kulkarni K, Prajeesh AG, Ashok K et al (2015) The IITM earth system model: transformation of a seasonal prediction model to a long-term climate model. Bull Am Meteorol Soc 96. DOI:10.1175/BAMS-D-13-00276.1

Taylor KE, Stouffer RJ, Meehl GA (2012) An overview of CMIP5 and the experiment design. Bull Am Meteor Soc 93(4):485-498. https:// doi.org/10.1175/BAMS-D-11-00094.1

Turner AG, Annamalai H (2012) Climate change and the South Asian summer monsoon. Nat Clim Chang 2:587. Available at https://doi. org/10.1038/nclimate1495

Undorf S, Polson D, Bollasina MA, Ming Y, Schurer A, Hegerl GC (2018) Detectable impact of local and remote anthropogenic aerosols on the 20th century changes of West African and South Asian monsoon precipitation. J Geophy Res (Atmos) 123:48714889. https://doi.org/10.1029/2017JD027711

van Vuuren DP, Edmonds J, Kainuma M, Riahi K, Thomson A, Hibbard K et al (2011) The representative concentration pathways: an overview. Clim Change 109:5-31. https://doi.org/10.1007/ s10584-011-0148-z

Vaughan DG, Comiso JC, Allison I, Carrasco J, Kaser G, Kwok R, Mote P, Murray T, Paul F, Ren J, Rignot E, Solomina O, Steffen K, Zhang T (2013) Observations: cryosphere. In: Stocker TF, Qin D, Plattner G-K, Tignor M, Allen SK, Boschung J, Nauels A, Xia Y, Bex V, Midgley PM (eds) Climate change 2013: the physical science basis. Contribution of working group I to the fifth assessment report of the intergovernmental panel on climate change

Xie S-P et al (2006) Role of narrow mountains in large-scale organization of Asian Monsoon Convection*. J Clim 19 (14):3420-3429. https://doi.org/10.1175/JCLI3777.1

You QL, Min J, Zhang W, Pepin N, Kang S (2015) Comparison of multiple datasets with gridded precipitation observations over the Tibetan Plateau. Clim Dyn 45:791-806

Wester P et al (eds) (2019) The Hindu Kush Himalaya Assessment. Springer International Publishing, Cham. https://doi.org/10.1007/ 978-3-319-92288-1 
Open Access This chapter is licensed under the terms of the Creative Commons Attribution 4.0 International License (http:// creativecommons.org/licenses/by/4.0/), which permits use, sharing, adaptation, distribution and reproduction in any medium or format, as long as you give appropriate credit to the original author(s) and the source, provide a link to the Creative Commons license and indicate if changes were made.
The images or other third party material in this chapter are included in the chapter's Creative Commons license, unless indicated otherwise in a credit line to the material. If material is not included in the chapter's Creative Commons license and your intended use is not permitted by statutory regulation or exceeds the permitted use, you will need to obtain permission directly from the copyright holder. 